\title{
MedChemComm
}

Check for updates

Cite this: Med. Chem. Commun. 2018, 9, 1779

Received 13th April 2018

Accepted 3rd August 2018

DOI: $10.1039 / \mathrm{c} 8 \mathrm{md} 00198 \mathrm{~g}$

rsc.li/medchemcomm

\section{Targeting Brd4 for cancer therapy: inhibitors and degraders}

\author{
Yingchao Duan, ${ }^{a}$ Yuanyuan Guan, ${ }^{a}$ Wenping Qin, ${ }^{a}$ Xiaoyu Zhai, ${ }^{a}$ \\ Bin Yu (D)*b and Hongmin Liu (D)*b
}

\begin{abstract}
Bromodomain-containing protein 4 (Brd4) plays an important role in mediating the expression of genes involved in cancers and non-cancer diseases such as inflammatory diseases and acute heart failure. Inactivating Brd4 or downregulating its expression inhibits cancer development, leading to the current interest in Brd4 as a promising anticancer drug target. Numerous Brd4 inhibitors have been studied in recent years and some of them are currently in various phases of clinical trials. Recently, selective degradation of target proteins by small bifunctional molecules (PROTACs) has emerged as an attractive drug discovery approach owing to the advantages it could offer over traditional small-molecule inhibitors. A number of Brd4 degraders have been reported and showed more efficient anticancer activities than just protein inhibition. In this review, we will discuss recent findings in the discovery and development of smallmolecule inhibitors and degraders that target Brd4 as a potential anticancer agent.
\end{abstract}

\section{Introduction}

Reversible lysine acetylation plays an essential role in the epigenetic regulation of chromatin structure and transcription of genes via modification of histone proteins and transcription factors. These changes in gene expression are modulated by three categories of epigenetic regulatory proteins, which are commonly known as "writers", "erasers", and "readers". Histone acetyltransferases (HATs) function as "writers" to acetylate lysine residues on histone tails, ${ }^{1}$ while histone deacetylases (HDACs) act as "erasers" to remove the acetyl group from acetylated lysine (Kac). ${ }^{2,3}$ The third kind of epigenetic regulatory protein is the bromodomain family of proteins that selectively bind to acetylated lysines, thus functioning as "readers" of the lysine acetylation state. ${ }^{4}$

The bromodomain and extra-terminal (BET) family is a subset of 46 bromodomain-containing proteins found only in the human genome. ${ }^{5}$ BET proteins are composed of four proteins, namely bromodomain-containing protein 2 (Brd2), $\operatorname{Brd} 3$, Brd4 and bromodomain testis-specific protein $(\operatorname{BrdT}){ }^{6}$ Each BET family member contains tandem $\mathrm{N}$-terminal bromodomains (BD1 and BD2) and an extra C-terminal domain (ET) exhibiting high levels of sequence conservation. ${ }^{7}$

\footnotetext{
${ }^{a}$ School of Pharmacy, Xinxiang Medical University, Xinxiang, Henan 453003, China

${ }^{b}$ Key Laboratory of Advanced Pharmaceutical Technology, Ministry of Education of China, Co-innovation Center of Henan Province for New Drug $R \& D$ and Preclinical Safety, Institute of Drug Discovery and Development, School of Pharmaceutical Sciences, Zhengzhou University, 100 Kexue Avenue, Zhengzhou, Henan 450001, China.E-mail: zzuyubin@hotmail.com, liuhm@zzu.edu.cn
}

Each bromodomain of Brd4 shares a conserved fold comprising a left-hand bundle of four antiparallel $\alpha$ helices $(\alpha \mathrm{A}, \alpha \mathrm{B}$, $\alpha \mathrm{C}$ and $\alpha \mathrm{Z}$ ) linked by two hydrophobic loop structures, namely the ZA loop formed between the $\alpha \mathrm{Z}$ and $\alpha \mathrm{A}$ helices and the BC loop formed between the $\alpha \mathrm{B}$ and $\alpha \mathrm{C}$ helices. The loop regions of Brd4 BD1 (Brd4(1)) and BD2 (Brd4(2)) diverge slightly in sequence and length which contributes to acetyllysine binding specificity. ${ }^{8}$ Cocrystal structures between $\operatorname{Brd4}(1)$ and peptidic substrates show that helices $\alpha \mathrm{B}$ and $\alpha \mathrm{C}$ and the ZA loop form a hydrophobic Kac-recognition pocket at the helical bundle terminus. The top of the pocket usually contains a well-conserved asparagine residue 140 (Asn140), which engages in a direct hydrogen bonding to the Kac. Simultaneously, a second hydrogen bond is formed between an acetyl carbonyl oxygen atom and the phenol of a conserved Tyr97 via a structured water molecule. A conserved hydrophobic region, the WPF shelf, formed among the ZA loop, BC loop and $\alpha \mathrm{Z}$, is also important for Brd4 binding affinities. ${ }^{6,9}$ Brd4 regulates gene expression through its ability to bind to Kac residues of histone tails, followed by recruiting the positive transcription elongation factor $\mathrm{b}$ (P-TEFb) to phosphorylate RNA polymerase II (RNA Pol II). ${ }^{10}$

Deregulation of BET proteins, in particular Brd4, has been implicated in the development of diverse diseases, especially cancers. ${ }^{11}$ Zuber et al. demonstrated that Brd4 played an important role in maintaining c-Myc expression to promote aberrant self-renewal of AML cells. Knockdown of Brd4 using shRNAs or pharmacologic inhibition of Brd4 with a smallmolecule inhibitor resulted in induction of terminal differentiation and elimination of leukemia stem cells and showed 
potent anti-leukemic effects in a variety of human AML cell lines and primary patient-derived cells. ${ }^{12,13}$ Hunter and colleagues identified $\mathrm{Brd4}$ as an inherited susceptibility gene that robustly predicted progression, metastasis and survival for breast cancer. Brd4 dynamically regulated breast cancer metastasis through modulation of the extracellular matrix gene expression. ${ }^{14,15}$ Malley et al. demonstrated that BET protein inhibition potently suppressed the growth of tamoxifen-resistant breast cancer cells. Co-treatment with BET inhibitor and the ER degrader fulvestrant in a tamoxifen-resistant breast cancer xenograft mouse model displayed a strong long-lasting anticancer effect. ${ }^{16}$ In NSCLC tissues and NSCLC cell lines with higher invasion and metastasis potentials, Brd4 expression was significantly up-regulated. Suppression of Brd4 expression in NSCLC cell lines impaired cell invasion, inhibited cell proliferation, and accelerated cell apoptosis. More importantly, a high level of Brd4 was closely correlated with the poor prognosis of NSCLC patients. ${ }^{17}$ Brd4 was highly over-expressed in primary and metastatic melanoma tissues and essential for melanoma tumor growth. Treatment with Brd4 inhibitors rapidly downregulated key cell-cycle genes, including $S K P 2, E R K 1$ and c-Myc, and strongly attenuated melanoma cell proliferation in vitro and tumor growth and metastatic behavior in vivo. Individual silencing of Brd4 mostly recapitulated the potent anti-leukemic effects of Brd4 inhibitor-mediated suppression. Notably, Brd4 inhibitor treatment remained robustly effective against $B R A F$ or NRAS mutant melanoma cells. ${ }^{18}$ Ayad et al. demonstrated that $\mathrm{Brd} 2$ and $\mathrm{Brd} 4$ were significantly elevated in glioblastoma (GBM). Depletion of Brd4 using siRNA in GBM cells significantly reduced GBM cell proliferation by arresting cell cycle progression at the $G_{1} / S$ phase. Similarly, treatment with the BET protein inhibitor I-BET151 inhibited GBM cell proliferation in vitro and in vivo. ${ }^{19}$ In castration-resistant prostate cancer (CRPC), knockdown of Brd2, 3 and 4 led to significant inhibition of cell proliferation and invasion, phenocopying the BET bromodomain inhibition treatment. In CRPC xenograft mouse models, BET inhibitors showed powerful anticancer activity and were more efficacious than direct AR antagonists. ${ }^{20}$

In view of the intimate link between Brd4 expression and cancers, Brd 4 has been considered as a promising therapeutic target in many malignancies. ${ }^{21,22}$ Significant efforts have been made to develop pharmacological inhibitors of $\operatorname{Brd} 4$, and a number of Brd4 inhibitors have progressed to clinical and preclinical evaluation. ${ }^{23,24}$ Recently, Brd4 degraders based on protein proteolysis-targeting chimera (PROTAC) technology have emerged as a novel approach for the epigenetic therapy of cancers and displayed exciting antitumor efficiency. Herein, we mainly focus on discussing recent advances in small-molecule inhibitors and degraders of Brd4 developed for cancer therapy.

\section{Brd4 inhibitors}

Since the first Brd4 inhibitor (+)-JQ1 was developed in 2010, numerous Brd4 inhibitors have been discovered in the past few years. According to the interaction mode between BDs and inhibitors, there are two classes of Brd4 inhibitors: monovalent and bivalent. Monovalent Brd4 inhibitors bind to each bromodomain of Brd4 protein separately. In contrast, bivalent Brd4 inhibitors are capable of engaging both bromodomains simultaneously within Brd4. The most widely studied Brd4 inhibitors are monovalent Brd4 inhibitors, which are mainly divided into the following eight categories according to the similarity of their chemical structures: triazoloazepine derivatives, isoxazole derivatives, pyridine derivatives, tetrahydroquinoline derivatives, triazolopyrazine derivatives, 4-acyl pyrrole derivatives, 2-thiazolidinone derivatives and others (Table 1). Moreover, several Brd4 inhibitors with disclosed structure have been enrolled into different phases of human clinical trials. $^{25}$

\subsection{Monovalent Brd4 inhibitors}

1.1.1 Triazoloazepine-based Brd4 inhibitors. Inspired by the observation from Mitsubishi Pharmaceuticals that simple thienodiazepines possessed binding activity for $\operatorname{Brd} 4$, Bradner et al. reported the first potent and selective BET protein inhibitor (+)-JQ1 (1) containing a thieno-triazolo-1,4diazepine scaffold (Fig. 1). The co-crystal structure showed that (+)-JQ1 entirely occupied the acetyl-lysine binding pocket by forming a hydrogen bond between the methyltriazole moiety and the conserved asparagine140. (+)-JQ1 strongly inhibited Brd4(1) with an $\mathrm{IC}_{50}$ value of $77 \mathrm{nM}$ and a $K_{\mathrm{d}}$ value of $50 \mathrm{nM}$, determined by alpha-screen and isothermal titration calorimetry (ITC) assays, respectively. In contrast, its enantiomer (-)-JQ1 showed no significant interaction with any BET proteins. In several NUT midline carcinoma xenograft models, remarkable tumor regression and prolonged overall survival were observed after treatment with (+)-JQ1 for 18 days at a well-tolerated dose. (+)-JQ1 also showed robust antitumor efficacy in several other xenograft models including multiple myeloma and AML. ${ }^{11,26}$ The development of (+)JQ1 revealed novel insights into the therapeutic potential of inhibiting Brd4 and aroused an upsurge of research on Brd4 inhibitors.

Exploring the effect of the substituent on the chain moiety of (+)-JQ1 led to a number of thienodiazepine-based Brd4 inhibitors. The representative compounds 2-6 are shown in Fig. 1. Among them, the two best known are OTX015 (2) ${ }^{27-29}$ and TEN-010 (3), ${ }^{30}$ which have entered a phase I clinical trial for the treatment of hematological malignancies and other cancers. Compound 4, patented by Tensha Therapeutics, ${ }^{31}$ and compound 5, patented by Bayer, ${ }^{32}$ exhibited potent inhibition against $\operatorname{Brd4(1)~with~an~} \mathrm{IC}_{50}$ value of $0.43 \mathrm{nM}$ and 27 $\mathrm{nM}$, respectively. Compound 6 was generated from a phenotypic drug discovery study on thienodiazepine derivatives and showed impressive $\operatorname{Brd4(1)}$ inhibitory activity with an $\mathrm{IC}_{50}$ value of $34 \mathrm{nM}$. In addition to robust in vivo antitumor efficacy with a tumor growth inhibition (TGI) of $80 \%$ at a dose of $10 \mathrm{mg} \mathrm{kg}^{-1}$ twice a day, compound 6 also displayed potent immunosuppressive activity in a mouse collagen-induced arthritis model. ${ }^{33}$ 
Table 1 Overview of small-molecule Brd4 inhibitors

\begin{tabular}{|c|c|c|c|c|c|c|}
\hline & Structure features & Compounds & Compounds in clinical trials & Clinical phase & NCT identifier & Ref. \\
\hline \multirow[t]{12}{*}{ Brd4 inhibitors } & & & & & NCT02698176 & \\
\hline & & & & & NCT01713582 & \\
\hline & & & 3 (TEN-010) & I & NCT02308761 & 30 \\
\hline & & & 10 (GSK525762, I-BET762) & $\mathrm{I} / \mathrm{II}$ & NCT01943851 & $20,35,36$ \\
\hline & & & & & NCT01587703 & \\
\hline & & & & & NCT02157636 & \\
\hline & & & & & NCT02158858 & \\
\hline & & & 28 (I-BET151) & I & NCT02630251 & 47,48 \\
\hline & & & 36 (PLX51107) & I & NCT02683395 & 53 \\
\hline & & & 38 (INCB0543294) & I/II & NCT02431260 & 55 \\
\hline & Pyridines & $43-55$ & 46 (ABBV-075) & I & NCT02391480 & 60,61 \\
\hline & Others & $78-85$ & 82 (BMS-986158) & I/II & NCT02419417 & 86 \\
\hline Bivalent & Triazolopyridazines & $86-89$ & 89 (AZD5153) & I & NCT03205176 & 94,95 \\
\hline Brd4 inhibitors & Triazoloazepines & 90 & & & & \\
\hline
\end{tabular}

A parallel but independent study from GlaxoSmithKline described a series of compounds with different substitutions on benzodiazepine as potent Brd4 inhibitors (Fig. 2). ${ }^{34}$ Compound 7 was initially developed as an ApoA1 upregulator with an $\mathrm{EC}_{170}$ of $0.22 \mu \mathrm{M}\left(\mathrm{EC}_{170}\right.$ is the concentration of compound resulting in a $70 \%$ increase in luciferase activity). However, subsequent research studies confirmed that the ApoA1 upregulation was caused by directly targeting BET proteins with a $\mathrm{pIC}_{50}$ of 6.3 for Brd4. Various chemical modifications on compound 7 were carried out to explore more potent BET inhibitors. Compound 8 with potent $\mathrm{Brd} 4$ inhibition $\left(\mathrm{pIC}_{50}\right.$ of 6.4) was generated; however, the remarkable Brd4 inhibition potency was counteracted by the fact that compound 8 was prone to undergo a ring-opening and hydrolysis reaction in an acidic aqueous solution $\left(T_{1 / 2}=0.23 \mathrm{~h}\right.$ at $\left.\mathrm{pH} 2\right)$. It was found that compound 8 bound to Brds in a highly stereospecific manner, as exemplified by the $(R)$-enantiomer $(+)-8$, which is 251 times more potent than the $(S)$-enantiomer

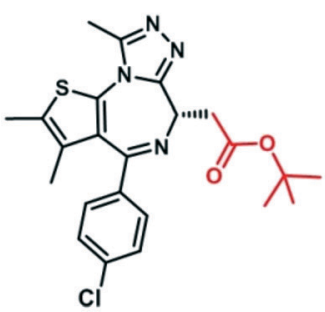

1, (+)-JQ-1

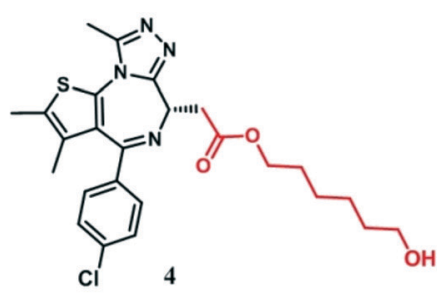

Brd4 (1) $K_{\mathrm{d}}: 0.43 \mathrm{nM}$

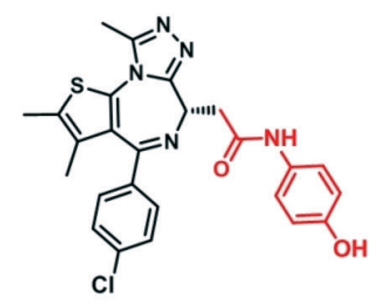

2, OTX015

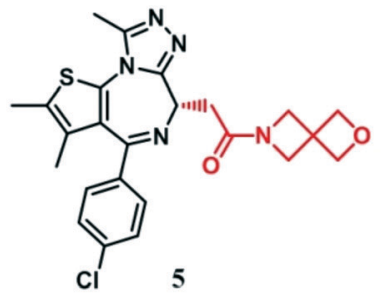

$\operatorname{Brd4}(1) \mathrm{IC}_{50}: 27 \mathrm{nM}$<smiles>Cc1sc2c(c1C)C(c1ccc(Cl)cc1)=N[C@@H](CC(N)=O)c1nnc(C)n1-2</smiles>

3, TEN-010

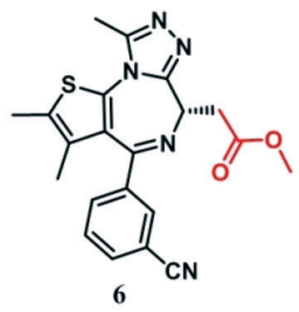

Brd4 (1) $\mathrm{IC}_{50}: 34 \mathrm{nM}$ TGI(HL-60): $80 \%$

Fig. 1 Reported thienotriazolodiazepine-based Brd4 inhibitors. 


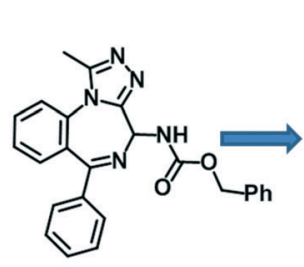

7

$\mathrm{Brd4} \mathrm{pIC}_{50}: 6.3$

ApoA1 EC $\mathrm{E}_{170}: 220 \mathrm{nM}$

Central BZDR $\mathrm{pIC}_{50}: 6.2$

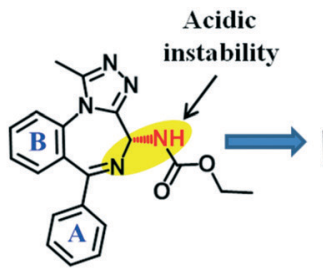

8

$\mathrm{Brd} 4 \mathrm{pIC}_{50}: 6.4$

$T_{1 / 2}$ (at pH 2): $0.23 \mathrm{~h}$

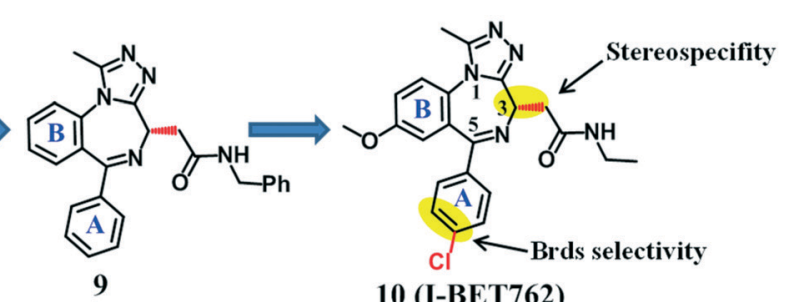

10 (I-BET762)

$\mathrm{Brd} 4 \mathrm{pIC}_{50}: 5.2$ $T_{1 / 2}$ (at pH 2): $>2$ h
Brd4 pIC ${ }_{50}: 6.2$

$T_{1 / 2}$ (mouse, dog, primate): $1.5,5.9,1.5 \mathrm{~h}$

$F$ (mouse, dog, primate): $61,44,52 \%$

Fig. 2 Discovery and development of Brd4 inhibitor I-BET762.

against Brd4. Compound 9 with improved acidic stability $\left(T_{1 / 2}>2 \mathrm{~h}\right.$ at $\left.\mathrm{pH} 2\right)$ was achieved by changing the carbamate group of compound 8 to an amide, but a 10-fold decrease in inhibition for Brd4 was observed.

Further modification of acid-stable compound 9 was focused on improving its potency and physiochemical properties. Substitution at the $p$ - or $m$-position of ring A abolished the off-target GABA receptor activity, which was derived from the 1,4-benzodiazepine motif found in many marketed GABA receptor-positive allosteric modulators. Higher potency and better drug-like properties were obtained by introducing a methoxyl substituent at the 8 position of the B ring and replacing the benzyl group with alkyl groups. All the favored modifications were incorporated into compound 9 and created a more druggable potent Brd4 inhibitor, compound 10 (namely I-BET762 or GSK525762), with excellent physicochemical and pharmacokinetic properties. I-BET762 displayed enhanced metabolic stability, good on-target Brd4 activity, excellent solubility, good tissue distribution, and good oral bioavailability $(44-61 \%$ in mice, dogs, and primates). Potent anticancer activity was observed for I-BET762 as an oral agent in several xenograft models. ${ }^{20,35}$ I-BET762 is currently under evaluation in a phase I/II clinical trial for the treatment of different cancers. ${ }^{36}$

By replacing the amide at the 3-position of I-BET762 with 1,3,4-oxadiazole, Bayer disclosed compound 11 (Fig. 3). ${ }^{37}$ Compound 11 showed potent anti-Brd4(1) activity $\left(\mathrm{IC}_{50}=20\right.$ $\mathrm{nM})$ and was very active against MOLM-13 cancer cells $\left(\mathrm{EC}_{50}\right.$ $=140 \mathrm{nM})$. Bayer also filed a patent for compounds 12 and 13, which were featured with triazolopyrazolodiazapine and triazolopyrrolodiazapine scaffolds, respectively. ${ }^{38}$ Compounds 12 and 13 were potent against $\mathrm{Brd} 4(1)\left(\mathrm{IC}_{50}=140\right.$ and $20 \mathrm{nM}$, respectively) and showed marked growth inhibition in multiple cell lines. Interestingly, researchers from Bayer found that<smiles>Cc1nnc(C[C@@H]2N=C(c3ccc(Cl)cc3)c3ccccc3-n3c(C)nnc32)o1</smiles>

$\operatorname{Brd4}(1) \mathrm{IC}_{50}: 20 \mathrm{nM}$<smiles>COC(=O)C[C@H]1N=C(c2ccc(Cl)cc2)c2nn(C)cc2-n2c(C)nnc21</smiles>

$\operatorname{Brd4}(1) \mathrm{IC}_{50}: 140 \mathrm{nM}$<smiles>Cc1c2c(cn1C)-n1c(C)nnc1[C@H](CC(=O)N1CC3(CCS3(=O)=O)C1)N=C2c1ccc(Cl)cc1</smiles>

$\operatorname{Brd4}(1) \mathrm{IC}_{50}: 20 \mathrm{nM}$

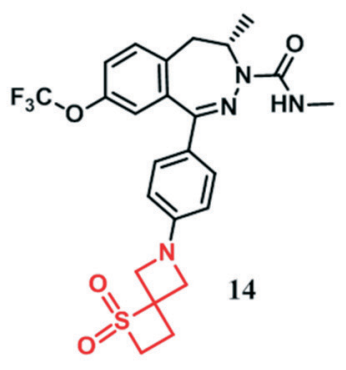

$\operatorname{Brd4}(1) \mathrm{IC}_{50}: 10 \mathrm{nM}$ MV4-11 IC $50: 30 \mathrm{nM}$<smiles>CNC(=O)N1N=C(c2ccc(N3CC4(CCS4(=O)=O)C3)cc2)c2cc(-n3nc(C)cc3C)ccc2C[C@H]1C</smiles>

$\operatorname{Brd4(1)}$ IC $_{50}: 10 \mathrm{nM}$ MV4-11 IC $50: 80 \mathrm{nM}$

Fig. 3 Chemical structures of compounds 11-15. 
isomeric benzodiazepine analogs without triazoles retained potency against Brd4. ${ }^{39}$ Two representative compounds, 14 and 15, demonstrated the same potent $\operatorname{Brd4}(1)$ inhibition with $\mathrm{IC}_{50}$ values of $10 \mathrm{nM}$ and inhibited the growth of MV411 cancer cells with $\mathrm{IC}_{50}$ values less than $100 \mathrm{nM}$.

1.1.2 Isoxazole-based Brd4 inhibitors. A fragment screen study from Albrecht et al. identified amino-isoxazole 16 as a weak Brd4(1) inhibitor with an $\mathrm{IC}_{50}$ of $33 \mu \mathrm{M}$. The cocrystal structure of $\operatorname{Brd4}(1)$ with compound 16 revealed that compound 16 could bind to Brd4(1) in a mode similar to that of (+)-JQ1. Inspired by this finding, novel isoxazole azepine compound 17 was developed by hybridizing the isoxazole motif with an azepine scaffold, which displayed potent $\operatorname{Brd}(1)$ inhibition $\left(\mathrm{IC}_{50}=290 \mathrm{nM}\right)$ and moderate c-Myc suppression activity in Raji cells $\left(\mathrm{IC}_{50}=2.1 \mu \mathrm{M}\right)$ (Fig. 4). ${ }^{40}$ Further modification of this compound led to 18 , which contained an amino group in place of the tert-butoxy group in compound $17 .{ }^{41} \mathrm{Com}-$ pound 18 demonstrated around 10-fold better potency than compound 17 against $\mathrm{Brd} 4(1)\left(\mathrm{IC}_{50}=26 \mathrm{nM}\right)$ and $\mathrm{c}-\mathrm{Myc}\left(\mathrm{IC}_{50}\right.$ = $140 \mathrm{nM}$ ). Compound 18 exhibited favorable pharmacokinetic profiles in rats with a $T_{1 / 2}$ of $1.4 \mathrm{~h}$ and a bioavailability of $31 \%$. P.O. dosing with compound 18 (10, 30, and $100 \mathrm{mg}$ $\mathrm{kg}^{-1}$ ) dose-dependently inhibited c-Myc mRNA expression in vivo, with an up to $75 \%$ reduction in c-Myc levels in the tumor at $4 \mathrm{~h}$ after a $100 \mathrm{mg} \mathrm{kg} \mathrm{kg}^{-1}$ dose. With the goal of avoiding the potential issue of metabolic instability, the thiophene ring in $\mathbf{1 8}$ was replaced with a more metabolically stable phenyl ring, and clinical candidate compound 19 (CPI0610) was gained. ${ }^{41}$ Compound 19 was proved to have similar potency to 18 against Brd4 and more desirable pharmacokinetic parameters. In vivo, oral treatment of an MV4-11 xeno- graft model with compound 19 caused substantial suppression of tumor growth with a maximum of $80 \%$ TGI at a dose of $30 \mathrm{mg} \mathrm{kg}^{-1}$ twice daily and showed no obvious body weight loss. In the same model, co-treatment with compound 19 (10 $\mathrm{mg} \mathrm{kg}{ }^{-1}$ subcutaneously twice daily) and doxorubicin (2 mg $\mathrm{kg}^{-1}$ intravenously twice weekly) for 28 days resulted in complete inhibition of tumor growth. In patients with heavily pretreated diffuse large B-cell lymphoma and follicular lymphoma, treatment with compound 19 led to meaningful antitumor effects. Introducing an acetamide-substituted pyrazole to the 8-position of compound 19 produced compound $20 .^{42}$ Compound 20 was potent against $\operatorname{Brd4}(1)\left(\mathrm{IC}_{50}=17 \mathrm{nM}\right)$ and c-Myc in MV4-11 cells $\left(\mathrm{IC}_{50}=32 \mathrm{nM}\right)$. In comparison to compound 19, compound 20 showed a longer half-life and greater bioavailability. In MV4-11 tumor xenografts in Balb/c nude mouse models, compound 20 effectively attenuated c-Myc mRNA levels at doses of 5 (50\% reduction) and $15 \mathrm{mg} \mathrm{kg}$ (75\% reduction) twice a day.

A parallel but separate work from Heightman's group disclosed the 3,5-dimethylisoxazole motif as a Brd4 inhibitor. $^{43}$ It was observed that compound 20 bound in the acetylated-lysine recognition pocket of the Brd4(1) by forming a key hydrogen bond between the oxygen of the dimethylisoxazole and $\mathrm{NH}_{2}$ of the conserved Asn 140 residue. Moreover, the dimethylisoxazole nitrogen atom interacts with the phenol group of Tyr-97 via the structured water molecule. The ethyl ether binds within the ZA channel and the methyl group attached to the secondary alcohol binds within the WPF shelf.

Replacing the methyl group with larger substituents such as aromatic rings to enhance the WPF shelf binding gave compounds 21 and 22. As expected, compared to compound
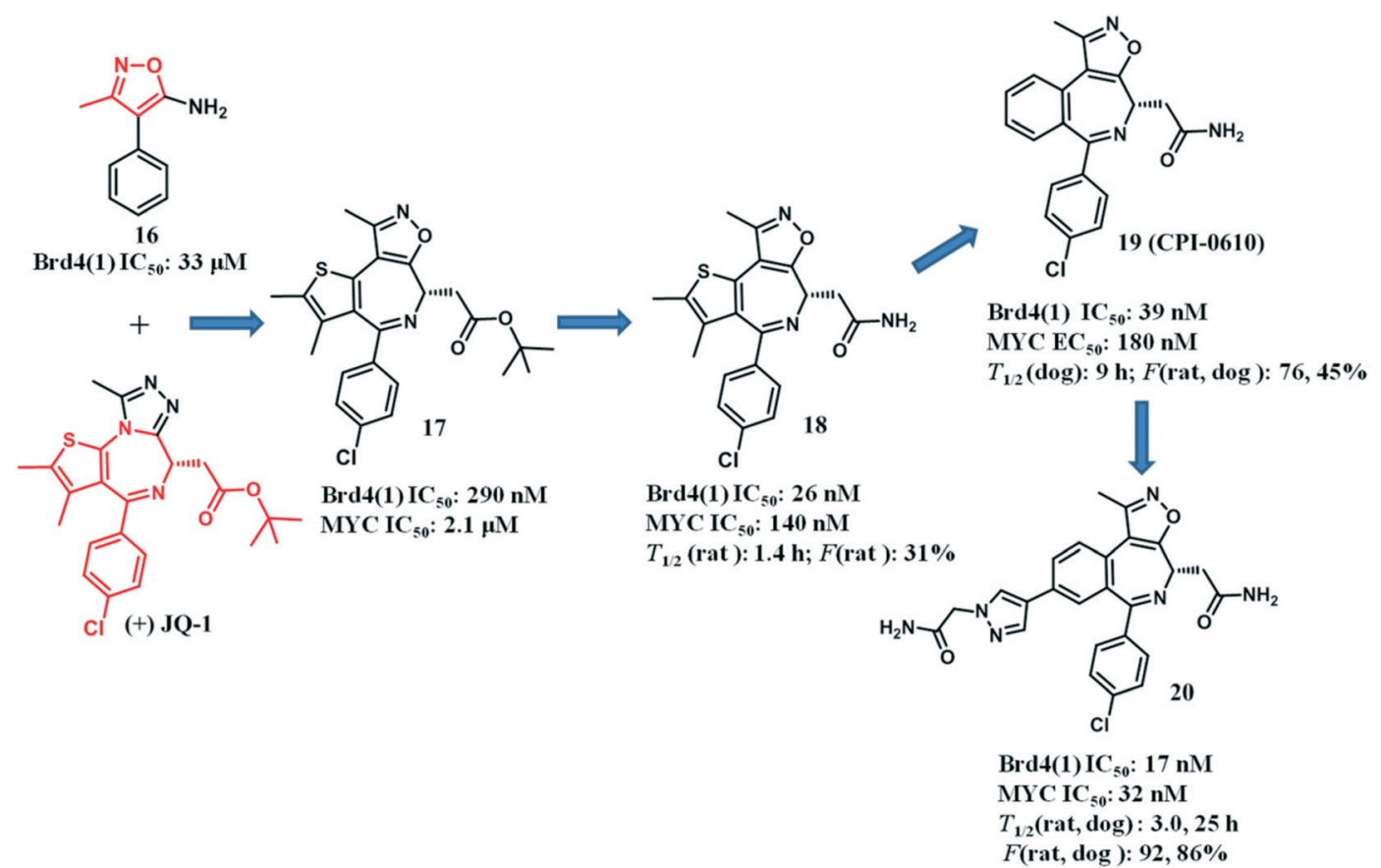

Fig. 4 Discovery and development of Brd4 inhibitor CPI-0610. 
20, both 21 and 22 had significant improvement in Brd4 binding affinity with $\mathrm{IC}_{50}$ values of 382 and $371 \mathrm{nM}$, respectively. ${ }^{44}$

Researchers from GSK developed compound 23 through structure-guided rational optimization of the privileged dimethylisoxazole chemotype. ${ }^{45}$ Compound 23 had an $\mathrm{IC}_{50}$ value of $0.5 \mu \mathrm{M}$ against Brd4 and showed good antiinflammatory activity in cellular assays, but poor solubility was observed. With the goal to improve the solubility, introduction of a polar group to the phenyl ring para to the isoxazole of 23 led to compound 24 , which had a slightly decreased potency $\left(\mathrm{IC}_{50}=2.6 \mu \mathrm{M}\right)$ but remarkable improved solubility as compared to compound 23.

Compound 25 was achieved using fluorous-tagged multicomponent reactions and showed robust Brd4 binding ability with a $K_{\mathrm{d}}$ of $550 \mathrm{nM}$ and cellular potency $\left(\mathrm{IC}_{50}=724 \mathrm{nM}\right)$ in Brd4-dependent lines. ${ }^{46}$ Notably, compound 25 potently bound to two other bromodomain-containing proteins including TAF1 $\left(\mathrm{IC}_{50}=560 \mathrm{nM}\right)$ and TAF1L $\left(\mathrm{IC}_{50}=1.3 \mu \mathrm{M}\right)$ (Fig. 5).

Most studies on 3,5-dimethylisoxazole-based Brd4 inhibitors have focused on introducing various heteroaromatic scaffolds to the 4-position of isoxazole.

Compound 26, which was initially developed as an ApoA1 up-regulator by utilizing a high-throughput screen approach, was proved to be a Brd4 inhibitor by researchers at GSK (Fig. 6). ${ }^{47,48}$ Optimizations of 26 to compound 27 created a more potent Brd4 inhibitor with an $\mathrm{IC}_{50}$ of $794 \mathrm{nM}$ but as well frustrating potent CYP2C9 and CYP3A4 inhibition $\left(\mathrm{IC}_{50}=2.8\right.$ and $3.9 \mu \mathrm{M}$, respectively). Improvement of selectivity over CYP450 was achieved by eliminating $\mathrm{CONH}_{2}$ and freezing the intramolecular hydrogen bond between C3 and C4 through a cyclization strategy to create a series of imidazolone analogues. Among them, I-BET151 (28) was the most promising Brd4 inhibitor $\left(\mathrm{IC}_{50}=794 \mathrm{nM}\right)$ with low CYP2C9 and CYP3A4 inhibition $\left(\mathrm{IC}_{50}=9.9\right.$ and $9.7 \mu \mathrm{M}$, respectively) and favorable PK properties suitable for oral exposure. I-BET151 demon- strated remarkable potency in two distinct mouse models of murine MLL-AF9 and human MLL-AF4 leukemia.

Compounds 29-31 with tricyclic scaffolds similar to that of I-BET151 were reported as potent Brd4 inhibitors in a patent from Trillium Therapeutics, with $\mathrm{IC}_{50}$ values in the range of 10-21 nM. ${ }^{49}$ It was found that the most potent compound $31\left(\mathrm{IC}_{50}=10 \mathrm{nM}\right)$ was quite unstable in both mouse and human liver microsomes due to the active $\mathrm{CH}_{2}$ position which was prone to metabolism.

With the goal of expanding the chemical diversity of Brd4 inhibitors and enhancing the solubility of previously developed isoxazoloquinoline $\operatorname{Brd} 4$ inhibitors (27, 28), Mirguet et al. synthesized a series of 1,5-naphthyridine derivatives by replacing the benzene ring of compound 20 with a naphthyridine system. ${ }^{50}$ Among them, compounds 32 and 33 showed the best $\mathrm{pIC}_{50}$ values for Brd4 (6.5 and 6.8, respectively) as well as good oral availability and solubility. Compounds 32 and 33 also showed efficacy in an acute inflammatory BALB/c mouse model.

Wang et al. reported a series of $\gamma$-carboline-containing compounds as novel small-molecule BET inhibitors (Fig. 6). ${ }^{51}$ The most potent inhibitor compound 34 bound to Brd2-4 proteins with $K_{\mathrm{i}}$ values of 3.2-24.7 $\mathrm{nM}$ as well as CREBBP protein with a $K_{\mathrm{d}}$ of $670 \mathrm{nM}$ and showed good specificity over eight other non-BET bromodomain-containing proteins $\left(K_{\mathrm{d}}\right.$ values $\geq 10$ $000 \mathrm{nM})$. Notably, compound 34 demonstrated remarkable cell growth inhibition activity and excellent cellular specificity in AML cell lines. Compound $\mathbf{3 4}$ potently inhibited the viability of MV4-11 and MOLM-13 cells containing the MLL1 fusion gene, with $\mathrm{IC}_{50}$ values of 20 and $66 \mathrm{nM}$, respectively, while it showed no obvious inhibitory potency $\left(\mathrm{IC}_{50}>2 \mu \mathrm{M}\right)$ against the $\mathrm{K} 562$ cell line harboring a Bcr-Abl fusion protein.

Recently, Wang's group developed novel BET inhibitors containing a $9 H$-pyrimido $[4,5-b]$ indole tricyclic core structure by inserting one extra nitrogen atom into the $5 \mathrm{H}$-pyrido[4,3-

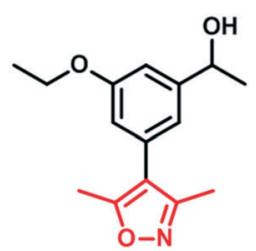

20

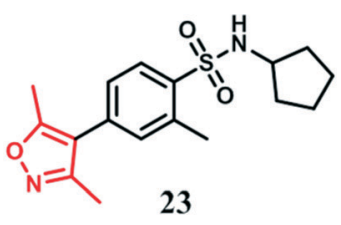

$\operatorname{Brd4}(1) \mathrm{IC}_{50}: 0.5 \mu \mathrm{M}$ Brd4(2) $\mathrm{IC}_{50}: 0.5 \mu \mathrm{M}$<smiles>Cc1noc(C)c1-c1cc(O)cc(C(O)c2ccccc2)c1</smiles>

21

$\operatorname{Brd4}(1) \mathrm{IC}_{50}: 0.382 \mu \mathrm{M}$

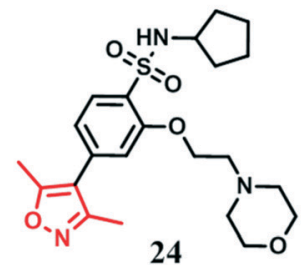

$\operatorname{Brd4}(1) \mathrm{IC}_{50}: 2.6 \mu \mathrm{M}$ $\operatorname{Brd4}(2) \mathrm{IC}_{50}: 1.5 \mu \mathrm{M}$<smiles>CC(=O)Oc1cc(-c2c(C)noc2C)cc(C(O)c2ccccc2)c1</smiles>

22

$\operatorname{Brd4}(1) \mathrm{IC}_{50}: 0.371 \mu \mathrm{M}$

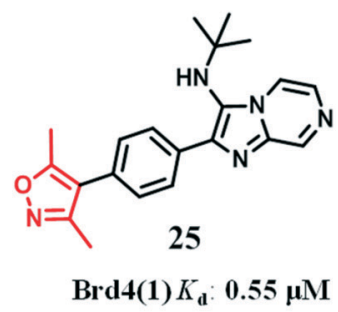

Fig. 5 Chemical structures of compounds 20-25. 


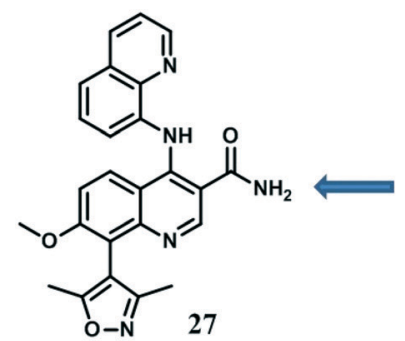<smiles>CCN(c1ccccc1)c1c(C(N)=O)cnc2c(-c3c(C)noc3C)c(OC)ccc12</smiles>

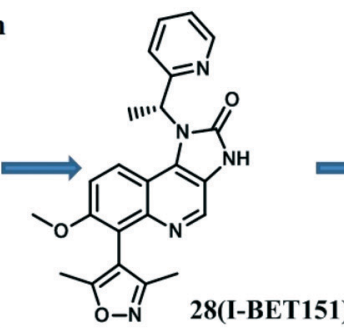<smiles></smiles>

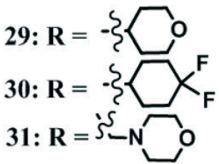
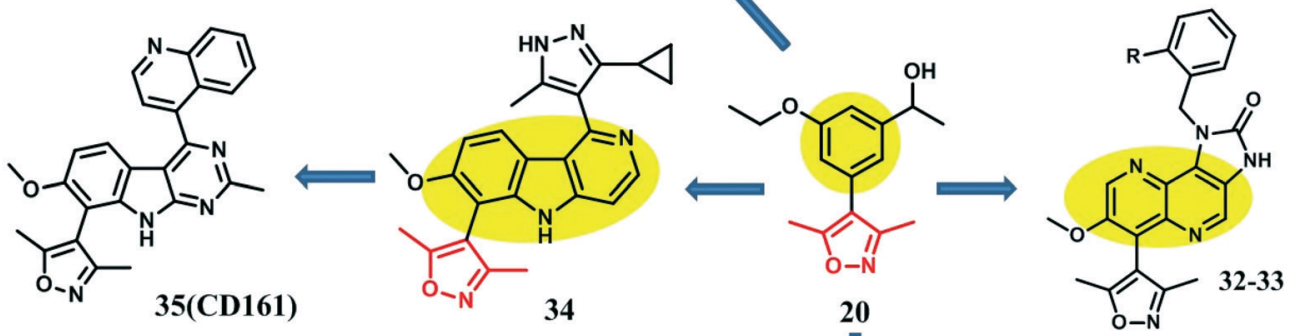

$32 \mathbf{R}=\mathbf{H}$

$33 \mathrm{R}=-\mathrm{OCF}_{3}$

$\downarrow$
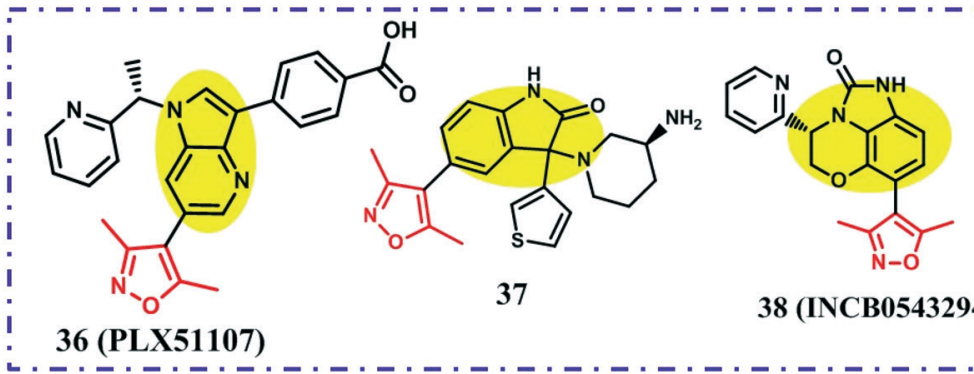

38 (INCB0543294)
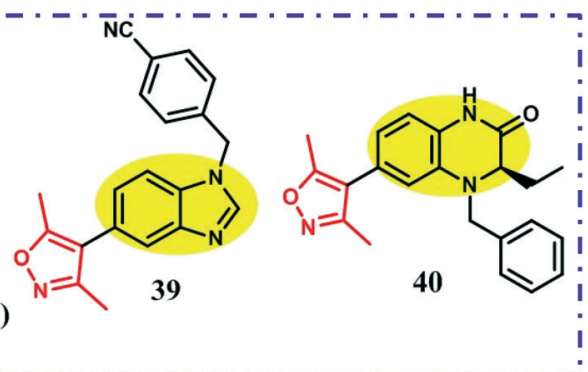

Fig. 6 Reported isoxazole-based Brd4 inhibitors.

$b$ ]indole of compound $34 .{ }^{52}$ A systematic SAR study led to the discovery of compound 35 , which bound to $\operatorname{Brd} 4(1)$ and Brd4(2) with $K_{\mathrm{i}}$ values of $8.2 \mathrm{nM}$ and $1.4 \mathrm{nM}$, respectively. Compound 35 showed significant activities in inducing the down-regulation of Brd4-downstream c-Myc gene and upregulation of p21 related to apoptosis in MV4-11 leukemia cells. This excellent Brd4 inhibition of compound 35 translated into dramatic antiproliferative effects against MV4-11 and MOLM-13 cell lines with $\mathrm{IC}_{50}$ values of 26 and $53 \mathrm{nM}$, respectively. In addition to acute leukemia cell lines, compound 35 also potently inhibited cell growth in nine breast cancer cell lines with $\mathrm{IC}_{50}$ values of $<1 \mu \mathrm{M}$. Compound 35 was found to have good solubility, microsomal stability in human microsomes and excellent oral bioavailability ( $93 \%$ in rat). In in vivo experiments, daily oral administration with compound 35 led to $>80 \%$ and complete tumor regression in the MV4-11 and MDA-MB-231 mouse xenograft model, respectively, without inducing any toxicity or decline in weight gain.

Hatice et al. described compound 36 (PLX51107) to be a potent Brd4 inhibitor. PLX51107 potently bound to Brd4(1) and Brd4(2) with $K_{\mathrm{d}}$ values of $1.7 \mathrm{nM}$ and $6.1 \mathrm{nM}$, respectively. ${ }^{53}$ PLX51107 could significantly suppress the CpGinduced proliferation of primary chronic lymphocytic leukemia (CLL) cells with $\mathrm{IC}_{50}$ values in the range of $0.156 \mu \mathrm{M}$ to 10 $\mu \mathrm{M}$. In a de novo mouse model of CLL, PLX51107 significantly reduced leukemic disease burden in peripheral blood and spleen at $20 \mathrm{mg} \mathrm{kg}^{-1}$ (oral daily) and was more effective than $50 \mathrm{mg} \mathrm{kg}^{-1}$ OTX015. PLX51107 is currently in phase I clinical studies for solid tumor, AML and myelodysplastic syndrome.

BeiGene Ltd. has patented a series of substituted 5-(3,5dimethylisoxazol-4-yl)indoline-2-one compounds including compound 37 as novel Brd4 inhibitors. Compound 37 inhibited Brd4 with an $\mathrm{IC}_{50}$ value of $8 \mathrm{nM}$ in a TR-FRET methodology and showed promising antiproliferation cellular activity against the MV4-11 cell line $\left(\mathrm{IC}_{50}=34 \mathrm{nM}\right) \cdot{ }^{54}$

Phillip et al. described the preclinical activity of a novel Brd4 inhibitor compound 38 (INCB054329) with low nanomolar potency against Brd4 for the potential treatment of malignant diseases. ${ }^{55}$ In both AML and lymphoma cell lines, INCB054329 remarkably inhibited expression of c-Myc, induced apoptosis consistent with increased expression of pro-apoptotic regulators, and suppressed cell growth with potencies of less than 200 $\mathrm{nM}$. Oral administration of INCB054329 showed potent in vivo antitumor efficiency in several models of hematologic cancers. At present, INCB054329 is being tested in patients with any advanced solid malignancy or lymphoma by Incyte.

In pursuit of a potent and rapidly accessible Brd4 inhibitor, Brennan's group developed benzimidazole-substituted 
3,5-dimethylisoxazoles as novel Brd4 inhibitors, which could be easily gained by three-step regioselective synthesis. ${ }^{56}$ The most potent compound, 39, had a Brd4(1) $\mathrm{IC}_{50}$ of $180 \mathrm{nM}$ and showed marked selectivity for CREBBP as well as seven other tested bromodomain-containing proteins.

Yang et al. reported compound $\mathbf{4 0}$ as a potent Brd4 inhibitor by replacing the benzo[ $[d]$ imidazole core of compound 39 with a dihydroquinoxalinone skeleton. ${ }^{57}$ This modification conferred an extra interplay with the ZA channel region and a stronger interaction with the WPF shelf, which were reflected in superior Brd4 inhibition activity $\left(\mathrm{IC}_{50}=70 \mathrm{nM}\right)$ and excellent antiproliferative activity in MV4-11 cancer cells $\left(\mathrm{IC}_{50}=\right.$ $258 \mathrm{nM}$ ) of compound 40.

More recently, Xu's group described a series of benzo[d] isoxazole-containing compounds as potent Brd4 inhibitors. ${ }^{58}$ Among them, compounds 41 and 42 showed the highest binding affinities to $\operatorname{Brd4}(1)$ with $K_{\mathrm{d}}$ values of 82 and $81 \mathrm{nM}$, respectively (Fig. 7). Thermal stability shift assay and BROMOscan revealed that compounds 41 and 42 exhibited excellent selectivity over other non-BET subfamily members. Compounds 41 and 42 demonstrated a good inhibitory effect against acute leukemia cell lines $\left(\mathrm{IC}_{50}: 0.4-0.68 \mu \mathrm{M}\right)$ and $\mathrm{AR}-$ positive prostate cancer cell lines ( $\left.\mathrm{IC}_{50}: 0.29-2.62 \mu \mathrm{M}\right)$, while they showed weak cytotoxicity in the AR-negative prostate cancer cells and normal lung fibroblast cell line HFL-1. Consistent with the cell viability assays, compounds 41 and 42 significantly inhibited the colony formation of $\mathrm{C} 4-2 \mathrm{~B}$ and 22Rv1 cells at $0.5 \mu \mathrm{M}$. In a C4-2B CRPC xenograft tumor model treated intraperitoneally five times a week with compounds 41 and 42 for 25 days at a dose of $50 \mathrm{mg} \mathrm{kg}{ }^{-1}$, TGI values of $70 \%$ and $51 \%$ were achieved, respectively.

1.1.3 Pyridone-based Brd4 inhibitors. Researchers at AbbVie identified a novel phenylpyridazinone fragment, com- pound 43, as a weak Brd4 binder $\left(K_{\mathrm{i}}=160 \mu \mathrm{M}\right)$ by a twodimensional NMR fragment screen. ${ }^{59}$ Compound 43 occupied the acetylated lysine binding pocket of Brd4(2) through two key interactions: hydrogen bonding of pyridone carbonyl oxygen to the amino group of conserved Asn433 and pyridone $N$-methyl substituent in the amphoteric pocket. Sustained efforts to achieve structural optimization of the privileged phenylpyridazinone moiety led to the discovery of a number of potent Brd4 inhibitors.

Compound 44 was found to potently bind to $\operatorname{Brd} 4$ with a $K_{\mathrm{i}}$ value of $13 \mathrm{nM}$ and exhibited significant antiproliferative activity against MX-1 cancer cells with an $\mathrm{EC}_{50}$ of $47 \mathrm{nM}$. A mouse study showed that an OPM-2 mouse xenograft model, dosed orally Q.D. with compound 44 for 21 days consecutively at doses of $1 \mathrm{mg} \mathrm{kg}^{-1}$ and $3 \mathrm{mg} \mathrm{kg}^{-1}$, demonstrated a TGI of $66 \%$ and $73 \%$, respectively. Further chemical modification led to the macrocycle compound 45 , which showed superior potency than compound $\mathbf{4 4}$ both in the cellular assay and in vivo assay. ${ }^{59}$

By fusing a pyrrole ring with the pyridine core of compound 44, McDaniel et al. described a series of novel Brd4 inhibitors featured with a pyrrolopyridone scaffold, which could bidentately interact with the conserved asparagine residue of the Brd4 protein, as exemplified by the clinical candidate compound 46 (ABBV-075). ${ }^{60}$ Compound 46 exhibited superior potency than compound 44 both in Brd4 binding assays $\left(K_{\mathrm{i}}=1.5 \mathrm{nM}\right)$ and antiproliferation effect on MX-1 cancer cells $\left(\mathrm{EC}_{50}=13 \mathrm{nM}\right)$. Compound 46 displayed favorable PK profiles with moderate oral bioavailability (50\%) and a fairly good oral half-life $\left(T_{1 / 2}=25 \mathrm{~h}\right)$ in humans. Compound 46 achieved a TGI of 99\% administered orally Q.D. at a dose of $1 \mathrm{mg} \mathrm{kg}{ }^{-1}$ for 25 days with acceptable tolerability (weight loss $\leq 10 \%$ ) in a Kasumi-1 AML mouse xenograft model, more

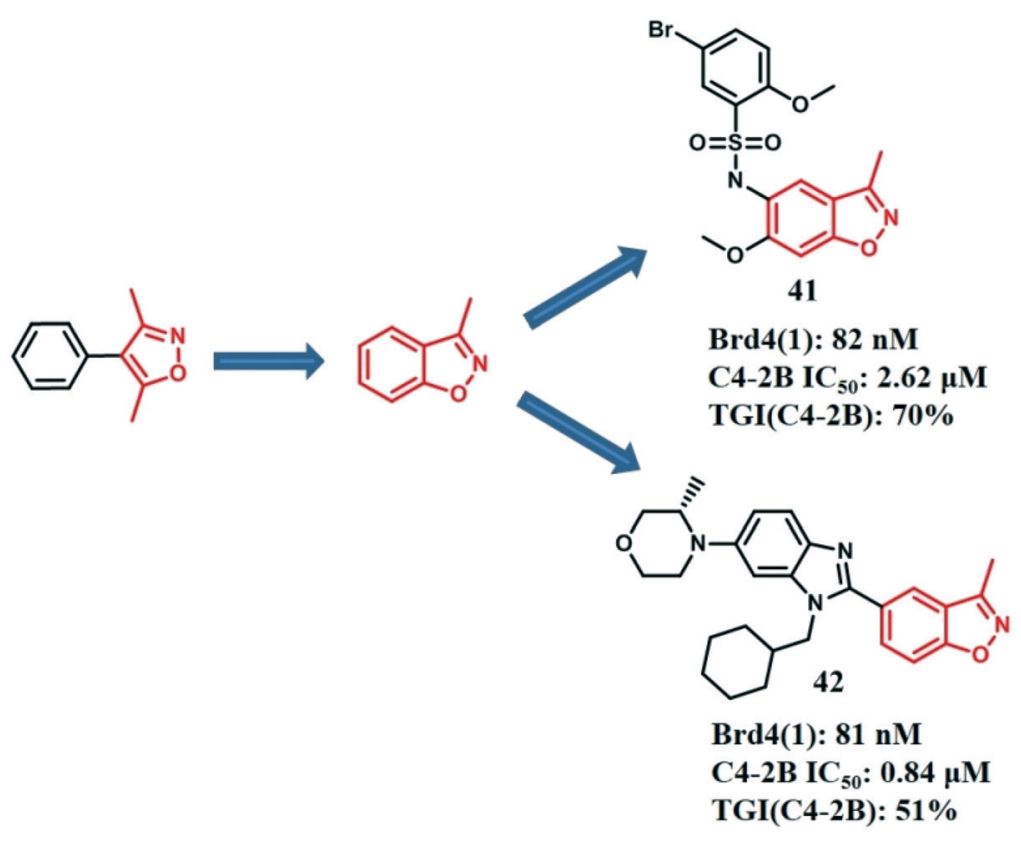

Fig. 7 Reported benzo[d]isoxazole-based Brd4 inhibitors. 
potent than 5 -azacitidine with a TGI of $78 \%$ at its maximum tolerated dose. Compound 46 at doses ranging from 1 to 2 $\mathrm{mg} \mathrm{kg}{ }^{-1}$ also demonstrated robust in vivo antitumor efficacy against both hematologic and solid tumors. ${ }^{61}$

A number of other pyridone-based potent Brd4 inhibitors including compounds 47-51 with $\mathrm{IC}_{50}$ values in the low nanomolar level have also been reported in patents (Fig. 8). ${ }^{62,63}$

AbbVie and Jubilant Biosys filed patents for a number of fused polycyclic pyridones as potent Brd4 inhibitors. ${ }^{64,65}$ Compounds 52-55, representatives of this design, demonstrated $\mathrm{Brd} 4(1) \mathrm{IC}_{50}$ values in single-digit nanomolar levels, and their good protein potency translated into the cellular assay. Both compounds 52 and 53 demonstrated an EC $_{50}$ of 16 $\mathrm{nM}$ in an MX-1 cellular assay and showed impressive efficacy in mouse tumor xenograft models. Compounds 54 and 55 displayed remarkable MV4-11 antiproliferative activity with $\mathrm{EC}_{50}$ values of $2.0 \mathrm{nM}$ and $8.0 \mathrm{nM}$, respectively (Fig. 9).

1.1.4 Tetrahydroquinoline-based Brd4 inhibitors. Compounds 56 and 57 were identified as novel $\mathrm{N}$-acetyllysine mimetics by Chung and co-workers via fragment-based screenings and were considered as appealing starting points to exploit novel Brd4 inhibitors due to their chemical tractability. ${ }^{66}$

GlaxoSmithKline developed a tetrahydroquinoline-based Brd4 inhibitor, compound 58 (I-BET726), on the basis of
$N$-acetyllysine mimetics compound $56 .^{67}$ Compound 58 showed high binding affinities to Brd4 with $K_{\mathrm{d}}$ values of 23 and $4.4 \mathrm{nM}$, confirmed by surface plasmon resonance (SPR) and isothermal titration calorimetry (ITC), respectively. Compound 58 demonstrated a high degree of selectivity against non-BET bromodomain-containing proteins as well as nonbromodomain targets. Moreover, it achieved a moderate elimination half-life and excellent oral bioavailability. Compound 58 strongly inhibited the proliferation of a panel of neuroblastoma cell lines with a median $\mathrm{IC}_{50}$ value of $75 \mathrm{nM}$. Oral administration of compound 58 to mouse xenograft models of human CHP-212 neuroblastoma resulted in downregulation of BCL2 and MYCN and a TGI of $82 \%{ }^{68}$

Novel tetrahydroquinoline-based Brd4 inhibitor compound 59 has been patented by GlaxoSmithKline and showed marked inhibition against $\operatorname{Brd} 4(2)$ with an $\mathrm{IC}_{50}$ value of less than $100 \mathrm{nM}$; however, it showed weak inhibition against Brd4(1). ${ }^{69}$ Compounds 60 and 61, patented by Forma Therapeutics $^{70}$ and Bayer, ${ }^{71}$ respectively, also displayed potent $\operatorname{Brd} 4$ inhibitory activity with $\mathrm{IC}_{50}$ values in the nanomolar range.

Fish et al. described the discovery of compound 62 through optimization of the hit compound $57 .^{72}$ Compound 62 displayed an $\mathrm{IC}_{50}$ value of $220 \mathrm{nM}$ against $\operatorname{Brd} 4(1)$ and inhibited IL-6 production in human blood mononuclear cells<smiles>Cn1cc(-c2cc(S(C)(=O)=O)ccc2N[C@H]2CC[C@H](NCc3ccc4ccccc4c3)CC2)c2cc[nH]c2c1=O</smiles>

Brd4(1) $K_{\mathrm{i}}: 1.1 \mathrm{nM}$ Brd4(2) $K_{\mathrm{i}}: 2.2 \mathrm{nM}$ MX-1 EC $_{50}: 10 \mathrm{nM}$

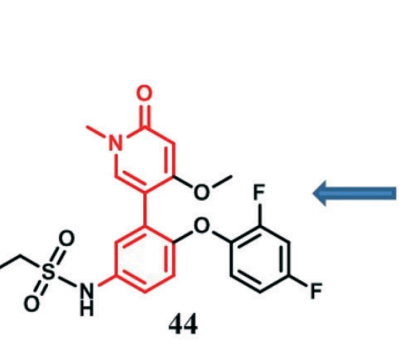

Brd4 $K_{\mathrm{i}}: 8.9 \mathrm{nM}$ MX-1 EC E0 $_{50}: 33$ nM TGI(OPM-2): $85 \%$

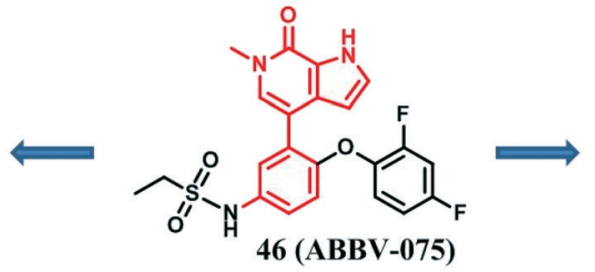

Brd4 $K_{\mathrm{i}}: 1.5 \mathrm{nM}$

MX-1 EC 50 : $13 \mathrm{nM}$ TGI(Kasumi-1): 99\%

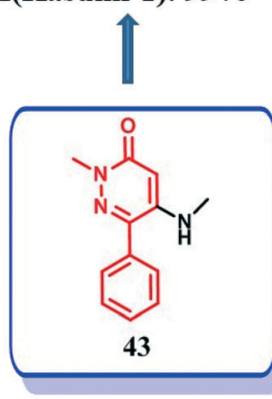

$\operatorname{Brd4} K_{\mathrm{i}}: 160 \mu \mathrm{M}$
Brd4 $K_{\mathrm{i}}: 13 \mathrm{nM}$
MX-1 EC $_{50}: 47 \mathrm{nM}$ TGI(OPM-2): $73 \%$

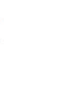

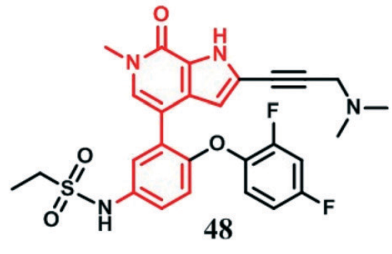

Brd4(1) $K_{\mathrm{i}}: 1.3 \mathrm{nM}$

Brd4(2) $K_{\mathrm{i}}: 3.3 \mathrm{nM}$

$\mathrm{MX}-1 \mathrm{EC}_{50}: 9.4 \mathrm{nM}$

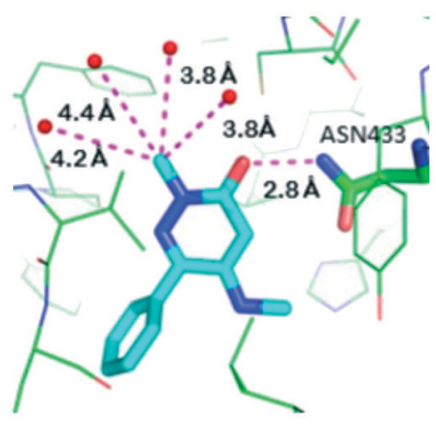

Compound 43 complexed with Brd4(2)
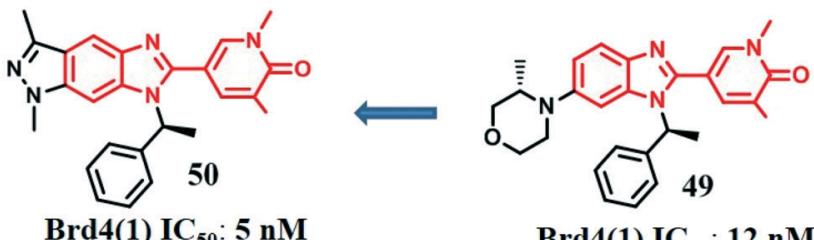

$\operatorname{Brd4(1)~} \mathrm{IC}_{50}: 12 \mathrm{nM}$

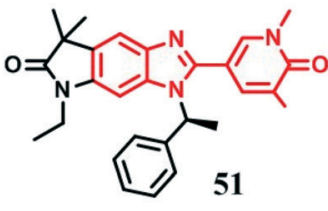

Brd4(1) IC $_{50}: 1.3 \mathrm{nM}$

Fig. 8 Reported pyridone-based Brd4 inhibitors. 
<smiles>Cn1cc2c3c(c[nH]c(=O)c31)CN(c1ccc(F)cc1F)c1ccc(CS(C)(=O)=O)cc1-2</smiles>

52

Brd4(1) $\mathrm{IC}_{50}: 1.8 \mathrm{nM}$

Brd4(2) $\mathrm{IC}_{50}: 2.0 \mathrm{nM}$

MX-1 EC E0 $_{50}: 16 \mathrm{nM}$

TGI(OPM-2): $81 \%$<smiles>Cn1cc2c3c(c[nH]c(=O)c31)CN(c1ccccn1)c1ccc(CS(C)(=O)=O)cc1-2</smiles>

53

Brd4(1) $\mathrm{IC}_{50}: 1.1 \mathrm{nM}$

Brd4(2) $\mathrm{IC}_{50}: 2.1 \mathrm{nM}$

MX-1 EC 50 $_{0}: 16 \mathrm{nM}$

TGI(OPM-2): $79 \%$<smiles>CCOC(=O)CC1N=C(c2ccc(Cl)cc2)c2cc(OC)ccc2-c2cn(C)c(=O)cc21</smiles>

54

Brd4(1) $\mathrm{IC}_{50}: 3.0 \mathrm{nM}$

MV4-11 $\mathrm{EC}_{50}: 2.0 \mathrm{nM}$<smiles>CCNC(=O)CC1N=C(C2CCCCC2)c2cc(OC)ccc2-c2cn(C)c(=O)cc21</smiles>

55

Brd4(1) $\mathrm{IC}_{50}: 2.0 \mathrm{nM}$

MV4-11 $\mathrm{EC}_{50}: 8.0 \mathrm{nM}$

Fig. 9 Reported fused polycyclic pyridone-based Brd4 inhibitors.

stimulated by LPS with an $\mathrm{EC}_{50}$ value of $1.89 \mu \mathrm{M}$. Compound 62 showed thermal shifts of 2.1-6.5 ${ }^{\circ} \mathrm{C}$ against BET proteins, while it showed thermal shifts of less than $1^{\circ} \mathrm{C}$ against three other tested bromodomain-containing proteins, indicating good selectivity for the BET bromodomains (Fig. 10).

1.1.5 Triazolopyrazine-based Brd4 inhibitors. A Boehringer Ingelheim Gmbh patent described Brd4 inhibitors predominantly extended on the triazolopyrazine scaffold; the representative compounds included compounds 63-66, which were recently highlighted in ACS Med. Chem. Lett. ${ }^{73}$ Compounds 63-66 displayed potent $\operatorname{Brd4(1)~inhibition~with~remarkable~}$ $\mathrm{IC}_{50}$ values in the single-digit nanomolar range (Fig. 11). ${ }^{74}$
Compound 67 and compounds 68-69 were obtained and patented by using a triazolopyridazine core ${ }^{75}$ or a triazolopyridine core ${ }^{76}$ as a bioisostere of triazolopyrazine, respectively. Compounds 67-69 showed low nanomolar potencies in inhibition of Brd4 and MV4-11 cancer cell growth.

1.1.6 4-Acyl pyrrole-based Brd4 inhibitors. Lucas et al. performed a high-throughput virtual screening campaign on Brd4 to identify novel inhibitors. This screening led to 22 hits whose binding affinity towards Brd4(1) was determined by ITC assay, identifying compound 70 bearing a 4-acyl pyrrole motif as the most potent hit against $\operatorname{Brd} 4(1)$ with a $K_{\mathrm{d}}$ value of 237 nM. ${ }^{77}$ Among 56 cell lines tested, compound 70 showed strong<smiles>CC(=O)N1c2ccc(-c3ccc(C#N)cc3)cc2[C@@H](Nc2ncccc2F)[C@H](C)[C@H]1C1CC1</smiles>

59 $\operatorname{Brd4}(2):<100 \mathrm{nM}$<smiles>CC(=O)N1c2ccc(-c3ccc(C(=O)O)cc3)cc2[C@@H](Nc2ccc(Cl)cc2)C[C@H]1C</smiles>

58 (I-BET726)

$\operatorname{Brd4} K_{\mathrm{d}}(\mathrm{SPR}): 23 \mathrm{nM}$ Brd4 $K_{\mathrm{d}}(\mathrm{ITC}): 4.4 \mathrm{nM}$

$T_{1 / 2}($ dog, primate): $1.8,2.7 \mathrm{~h}$

$F($ dog, primate): $80,100 \%$

TGI(CHP-212): $82 \%$<smiles>CC(=O)N1c2ccc(-c3ccc(-c4cnn(C5CC5)c4)c(OC[C@@H]4CC4(F)F)c3)cc2CCC1C</smiles>

Brd4(1) : $<100 \mathrm{nM}$ $\operatorname{Brd4}(2):<50 \mathrm{nM}$<smiles>C[C@H]1C(=O)N(C)c2ccc(-c3ccc(Nc4cccc(S(=O)(=O)N(C)C)c4)cc3)nc2N1C1CCN(C)CC1</smiles>

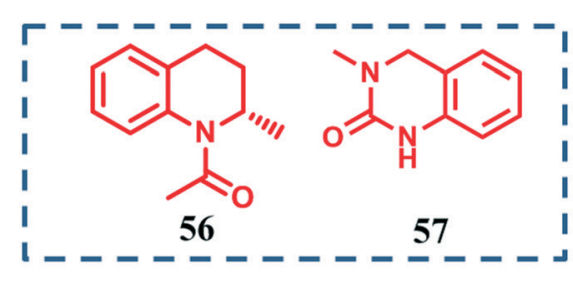

56 Brd4 IC 50 : 35\% inhibition@50 $\mu \mathrm{M}$ 57 Brd4 IC I0 $_{0}: 25 \%$ inhibition@50 $\mu \mathrm{M}$<smiles>COc1ccccc1S(=O)(=O)Nc1ccc2c(c1)CN(C)C(=O)N2</smiles>

Brd4 $\mathrm{IC}_{50}: 220 \mathrm{nM}$

Fig. 10 Reported tetrahydroquinoline-based Brd4 inhibitors. 
<smiles>CNc1nc(-c2nn(C)c(C)c2O)cn2c(C)nnc12</smiles>

63

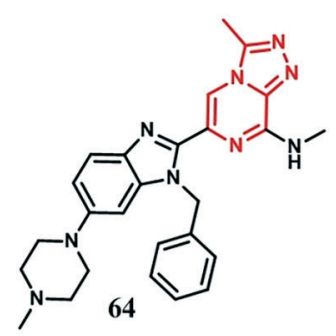

$\operatorname{Brd4}(1) \mathrm{IC}_{50}: 9 \mathrm{nM}$<smiles>CNc1nc(-c2nc3ccc(N4CCOCC4)cc3n2Cc2ccccc2)cn2c(C)nnc12</smiles>

65

$\operatorname{Brd4}(1) \mathrm{IC}_{50}: 5 \mathrm{nM}$<smiles>Cc1nnc2c(NC(C)C)nc(-c3nc4cnc(N5CCOCC5)cc4n3Cc3ccc(F)cn3)cn12</smiles>

Brd4(1) IC $_{50}: 1 \mathrm{nM}$<smiles>Cc1nn(C2CC2)c2c1C(=O)N(c1cc(C)c3nnc(C)n3n1)[C@H]2c1ccc(Cl)cc1</smiles>

Brd4 IC s0 $_{50}: 11 \mathrm{nM}$

MV4-11 IC $_{50}: 3.4 \mathrm{nM}$<smiles></smiles>

Brd4 $\mathrm{IC}_{50}: 12 \mathrm{nM}$

MV4-11 GI $\mathrm{I}_{50}: 2.9 \mathrm{nM}$

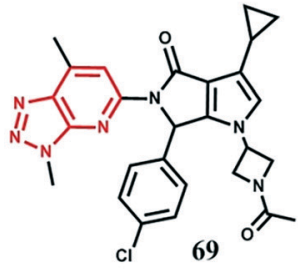

Brd4 $\mathrm{IC}_{50}:<11 \mathrm{nM}$

MV4-11 GI 5 $_{0}: 0.3 \mathrm{nM}$

Fig. 11 Reported triazolopyrazine-based Brd4 inhibitors.

inhibitory potency and selectivity towards leukemia cells, with a maximum $65 \%$ growth inhibition at $10 \mu \mathrm{M}$ against HL-60 cancer cells. A structure-guided modification of compound 70 performed based on the cocrystal structure of Brd4(1)/70 led to Brd4 inhibitors 71 and 72 with $K_{\mathrm{d}}$ values of 0.46 and $0.81 \mu \mathrm{M}$, respectively; however, both were less potent than compound 70 (Fig. 12). ${ }^{78}$

AbbVie published a patent application describing 4-acyl pyrrole-based Brd4 inhibitors, as represented by compound 73, which was potent both biochemically $\left[\operatorname{Brd} 4(1) K_{\mathrm{i}}=38 \mathrm{nM}\right.$, $\left.\operatorname{Brd4}(2) K_{\mathrm{i}}=225 \mathrm{nM}\right]$ and in the MX-1 cell line $\left(\mathrm{EC}_{50}=433\right.$ nM). ${ }^{79}$ Compound 74, patented also by AbbVie, exhibited $K_{\mathrm{i}}$ values of $15 \mathrm{nM}$ and $43 \mathrm{nM}$ against $\operatorname{Brd} 4(1)$ and $\operatorname{Brd} 4(2)$, re- spectively. Compound 74 was potently active against the MX1 cell line with an $\mathrm{EC}_{50}$ value of $160 \mathrm{nM}$, which translated into in vivo efficacy with a TGI of $80 \%$ at a dose of $100 \mathrm{mg}$ $\mathrm{kg}^{-1}$ in an MX-1 mouse xenograft model. ${ }^{80}$

1.1.7 2-Thiazolidinone-based Brd4 inhibitors. Shen's group described compound 76 as a novel Brd4 inhibitor, which was synthesized based on the novel $\mathrm{N}$-acetyllysine mimic compound 75 featured with a 2-thiazolidinone core. ${ }^{81}$ Compound 76 displayed $\operatorname{Brd4}(1)$ inhibition with an $\mathrm{IC}_{50}$ of $4.1 \mu \mathrm{M}$ and had good metabolic stability, but showed weak proliferation inhibition activity in HT-29 cancer cells with a GI $_{50}$ of $47.8 \mu \mathrm{M}$. Subsequent optimization by replacing the sulfonylaminophenyl substitution of 76 with an amino sulfonyl

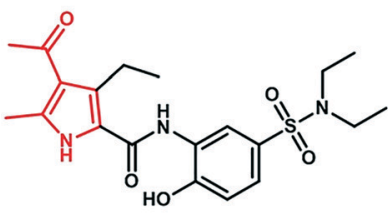

70 (XD14)

Brd4(1) $K_{d}: 237 \mathrm{nM}$

GI\%(HL-60) : 65\%@10 $\mu \mathrm{M}$

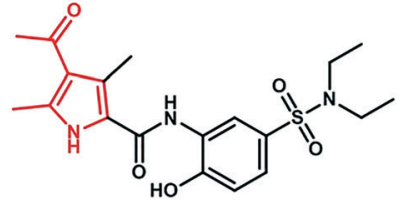

71

$\operatorname{Brd4}(1) K_{\mathrm{d}}: 460 \mathrm{nM}$<smiles>CCN(CC)S(=O)(=O)c1ccc(O)c(NC(=O)c2[nH]c(C)c(C(N)=O)c2C)c1</smiles>

72

Brd4(1) $K_{\mathrm{d}}: 810 \mathrm{nM}$<smiles>Cc1[nH]c(-c2ccccc2NC2CCCCC2F)cc1C(N)=O</smiles>

$\operatorname{Brd4}(1) K_{\mathrm{i}}: 38 \mathrm{nM}$

$\operatorname{Brd4(2)} K_{\mathrm{i}}: 225 \mathrm{nM}$

MX-1 EC $_{50}: 433 \mathrm{nM}$

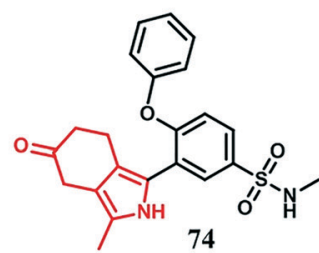

$\operatorname{Brd4}(1) K_{\mathrm{i}}: 15 \mathrm{nM}$

$\operatorname{Brd4}(2) K_{\mathrm{i}}: 43 \mathrm{nM}$

MX-1 EC E0 $_{50}: 160 \mathrm{nM}$

Fig. 12 Reported 4-acyl pyrrole-based Brd4 inhibitors. 
phenyl group gave compound 77 with an $\mathrm{IC}_{50}$ of $140 \mathrm{nM}$, which was about 30 times more potent than compound $76 .^{81}$ Compound 77 was found to exhibit potent activity against the proliferation of two leukemia cell lines and one colon cancer cell line with $\mathrm{IC}_{50}$ values ranging from 184 to $860 \mathrm{nM}$ (Fig. 13).

1.1.8 Other reported Brd4 inhibitors. Other selected examples of Brd4 inhibitors are listed in Fig. 14. Xu and coworker reported the discovery of the benzo[cd]indol-2(1H)-one scaffold as a new class of BET bromodomain inhibitors via a structure-based virtual screening approach and subsequent extensive chemical optimization. ${ }^{82}$ Among them, representative compound 78 showed robust binding affinity to $\operatorname{Brd4(1)}$ with a $K_{\mathrm{d}}$ value of $137 \mathrm{nM}$ and excellent selectivity over other non-BET bromodomain-containing proteins in the ITC assay. In MV4-11 leukemia cells and HL-60 cancer cells, compound 78 exhibited reasonable antiproliferation effects with $\mathrm{IC}_{50}$ values of $1.30 \mu \mathrm{M}$ and $2.99 \mu \mathrm{M}$, respectively. Oral administration with compound 78 in rats demonstrated good pharmacokinetic profiles with high oral bioavailability $(76.8 \%)$ and a moderate half-life $\left(T_{1 / 2}=3.95 \mathrm{~h}\right)$.
William's group disclosed dihydropyridopyrimidine derivative 79 as a novel Brd4 inhibitor, which was facilely generated in a single step from commercially available starting materials. ${ }^{83}$ Compound 79 had a $K_{\mathrm{i}}$ of $110 \mathrm{nM}$ for $\operatorname{Brd4(1)}$ and strongly inhibited the growth of MM1.S cells with an $\mathrm{IC}_{50}$ value of $0.46 \mu \mathrm{M}$. Compound 79 also demonstrated potent binding affinity to $\operatorname{BrdT}(1)$ with a $K_{\mathrm{i}}$ of $200 \mathrm{nM}$. Compound 79 was identified as the best $\operatorname{Brd} 4$ inhibitor $\left(\mathrm{IC}_{50}=0.43 \mu \mathrm{M}\right)$ with good selectivity over other BET family proteins.

Compound 80 markedly inhibited Brd4 and its downstream target c-Myc, induced ATG5-dependent autophagy via blocking Brd4-AMPK (AMP-activated protein kinase) interaction and displayed potent antiproliferative activity in breast cancer cell lines $\left(\mathrm{MCF}-7, \mathrm{IC}_{50}=1.62 \mu \mathrm{M}\right.$; MDA-MB-231, $\mathrm{IC}_{50}=$ $3.27 \mu \mathrm{M})$. Moreover, in in vivo efficacy evaluations of MCF-7 and MDA-MB-231 xenograft models, compound 80 showed substantial antitumor activity with a TGI of $80 \%$ and $76 \%$ after intragastric administration of $100 \mathrm{mg} \mathrm{kg}^{-1}$, respectively, without causing significant loss of body weight and toxicity. $^{84}$<smiles>C=CCCCCCC</smiles><smiles>C=CC=C</smiles>

Brd4 (1) $\mathrm{IC}_{50}: 4.1 \mu \mathrm{M}$

GI $_{50}($ HT-29) : $47.8 \mu \mathrm{M}$

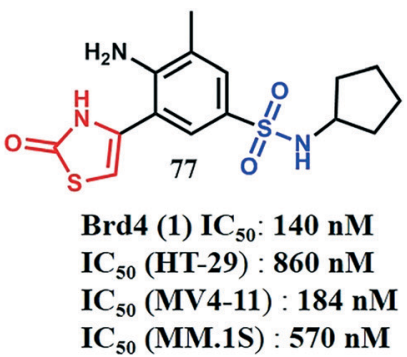

Fig. 13 Reported 2-thiazolidinone-based Brd4 inhibitors.

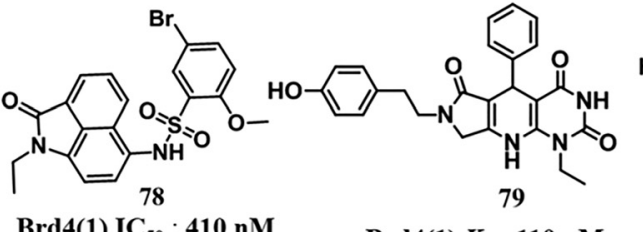

Brd4(1) $\mathrm{IC}_{50}: 410 \mathrm{nM}$ Brd4(1) $K_{\mathrm{d}}: 130 \mathrm{nM}$ $F($ rat): $76.8 \%$ $T_{1 / 2}($ rat $): 3.95 \mathrm{~h}$

$\operatorname{Brd4}(1) K_{1}: 110 \mathrm{nM}$ $\operatorname{BrdT}(1) K_{\mathrm{i}}: 200 \mathrm{nM}$<smiles>Cc1nnn(C)c1-c1cnc2c3ccc(C(C)(C)C)cc3n([C@H](c3ccccc3)C3CCOCC3)c2c1</smiles>
82 (BMS-986158)

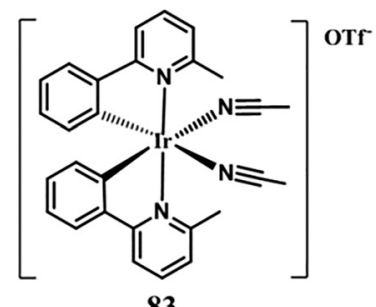

83

Brd4(1) $\mathrm{IC}_{50}: 70 \mathrm{nM}$

Brd4(2) $I_{50}:$ No inhibition

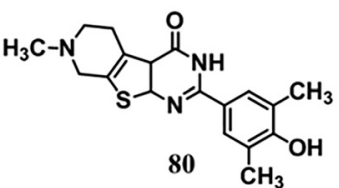

Brd4(1) $\mathrm{IC}_{50}: 430 \mathrm{nM}$ $\operatorname{Brd4}(2) \mathrm{IC}_{50}: 930 \mathrm{nM}$ TGI(MCF-7): $80 \%$ TGI(MDA-MB-231): 76\%
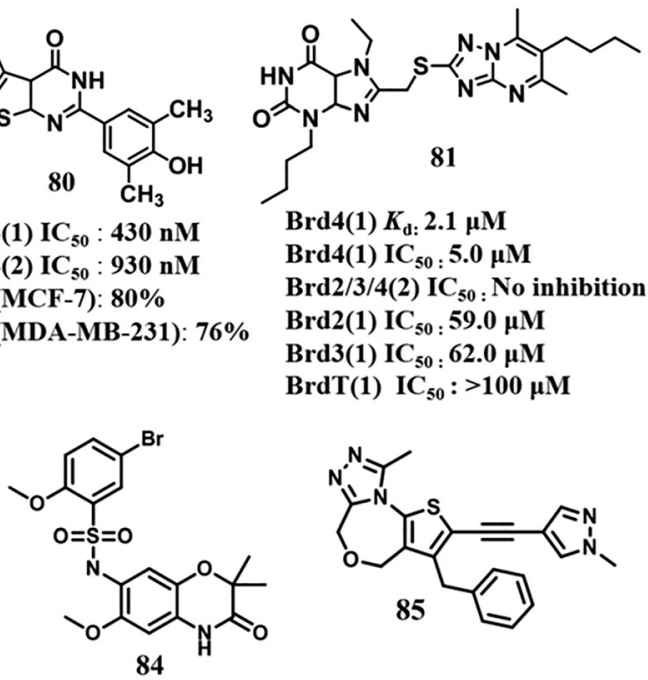

Brd4(1) IC $_{50}: 690 \mathrm{nM}$

Brd4(1) $K_{d}: 302$ nM

$F($ rat): $61.5 \%$

$T_{1 / 2}$ (rat): $1.96 \mathrm{~h}$

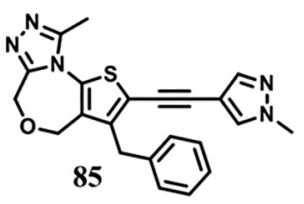

Brd4(1) $\mathrm{IC}_{50}: 10 \mathrm{nM}$

Brd4(1) $K_{\mathrm{i}}: 2.3 \mathrm{nM}$

Brd4(2) IC $_{50}: 66.6 \mathrm{nM}$

Brd4(2) $K_{\mathrm{i}}: 18.5 \mathrm{nM}$

Fig. 14 Other reported Brd4 inhibitors. 
Through a midthroughput screen, a xanthine derivative compound 81 was identified as a Brd4 inhibitor with a $K_{\mathrm{d}}$ of $2.1 \mu \mathrm{M}$ determined by ITC. Despite compound 81 showing weak cellular activity against Jurkat T cells with an $\mathrm{EC}_{50}$ of 27 $\mu \mathrm{M}$, impressive selectivity for $\operatorname{Brd4}(1)\left(\mathrm{IC}_{50}=5.0 \mu \mathrm{M}\right)$ over $\operatorname{Brd2} / 3(1)\left(\mathrm{IC}_{50}>50 \mu \mathrm{M}\right)$ and $\operatorname{BrdT}(1)\left(\mathrm{IC}_{50}>100 \mu \mathrm{M}\right)$ was observed; more unexpectedly, compound 81 showed no detectable inhibition against the BD2 counterparts of all BET proteins tested. $^{85}$

Compound 82 (BMS-986158) is a novel Brd4 smallmolecule inhibitor developed by Bristol-Myers Squibb and is currently being tested as monotherapy or in combination with nivolumab in subjects with selected advanced solid tumors or hematologic malignancies. However, to date, no clinical data on BMS-986158 have been published in peerreviewed journals. ${ }^{86}$

Zhong et al. identified an iridium(III) complex as the first metal-based, irreversible Brd4 inhibitor, compound $83 .^{87}$

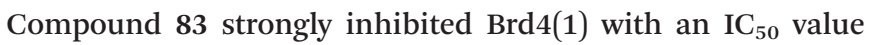
of $70 \mathrm{nM}$ in a TR-FRET assay, while it showed no significant inhibition against Brd4(2). ChIP analysis and immunoblotting analysis revealed that compound 83 could disrupt the binding of Brd4 to the c-Myc and Bcl-2 promoters and reduced the expression of c-Myc and $\mathrm{Bcl}-2$ in $\mathrm{A} 375$ and A2058 cancer cells. In a xenograft mouse model of human A375 melanoma cells, compound 83 significantly repressed tumor growth (a 40\% reduction of tumor volume) without causing visible toxicity at a dose of $100 \mathrm{mg} \mathrm{kg}^{-1}$ once daily for 16 days.

Xu's group designed and synthesized a series of 2,2dimethyl-2H-benzo $[b][1,4]$ oxazin-3 $(4 H)$-one derivatives and evaluated their Brd4 inhibitory activities, obtaining several compounds as potent $\mathrm{Brd} 4$ inhibitors with $\mathrm{IC}_{50}$ values in the nanomolar range. ${ }^{88}$ The representative compound 84 potently inhibited Brd4(1) with an $\mathrm{IC}_{50}$ value of $690 \mathrm{nM}$ and a $K_{\mathrm{d}}$ value of $302 \mathrm{nM}$ determined by an ITC experiment. Compound $\mathbf{8 4}$ showed good inhibition against a panel of prostate cancer cell lines, including C4-2B, LNCaP, and 22Rv1, with $\mathrm{IC}_{50}$ values in the range of 3.23-4.51 $\mu \mathrm{M}$, and potently inhibited 22Rv1 cancer cell colony formation in a dose-dependent manner. Oral dosing with compound 84 in rats demonstrated reasonable pharmacokinetic properties with a $T_{1 / 2}$ value of 1.96 $\mathrm{h}$ and an oral bioavailability of $61.5 \%$.

Wang's group described a series of $[1,4]$ oxazepine derivatives as a new class of Brd4 inhibitors. The most potent, compound 85, bound to Brd4(1) with a $K_{\mathrm{i}}$ value of $2.3 \mathrm{nM}$ and an $\mathrm{IC}_{50}$ value of $10 \mathrm{nM}$ and was more potent than OTX015. Consistent with its high binding affinities to Brd4, compound 85 was an effective inhibitor of cell growth, with $\mathrm{IC}_{50}$ values of 55.8, 207, and $173 \mathrm{nM}$ in the MV4-11, MOLM-13, and RS4-11 cell lines, respectively. ${ }^{89}$

\subsection{Bivalent Brd4 inhibitors}

Waring and colleagues demonstrated a series of triazolopyridazine-containing compounds, which were capable of binding both Brds in a single Brd4 protein simultaneously. ${ }^{90}$ The first bivalent Brd4 inhibitor, compound 87, was accidentally generated based on the structure optimization of AZD3514 (86), an androgen receptor (AR) modulator (Fig. 15). ${ }^{91,92}$ Despite its increased AR down-regulation potency, however, compound 87 induced estrogen receptor- $\alpha$ $(\mathrm{ER} \alpha)$ down-regulation, indicating that the direct target of compound 87 might not be AR. Considering the structural similarity between compound 87 and Brd4 inhibitor IBET762, a panel of Brd inhibition assays were performed. Compound 87 displayed potent inhibition against $\operatorname{Brd} 4(1)$ and $\operatorname{Brd4}(2)$ with $\mathrm{p} K_{\mathrm{d}}$ values of 7.2 and 6.1, respectively. Compound 87 suppressed c-Myc levels, inhibited cell growth and induced apoptosis more effectively in several Brd4-sensitive

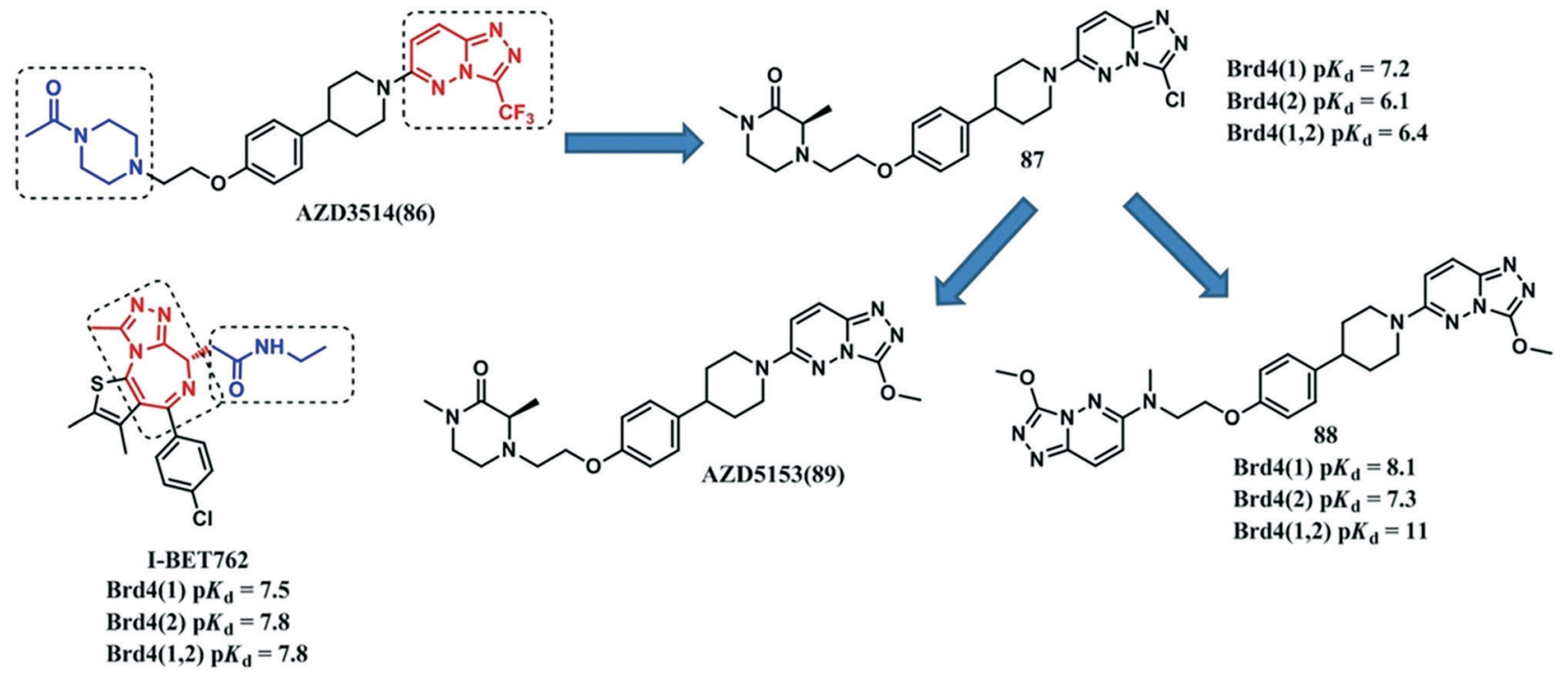

Fig. 15 Discovery and development of bivalent Brd4 inhibitor 89. 

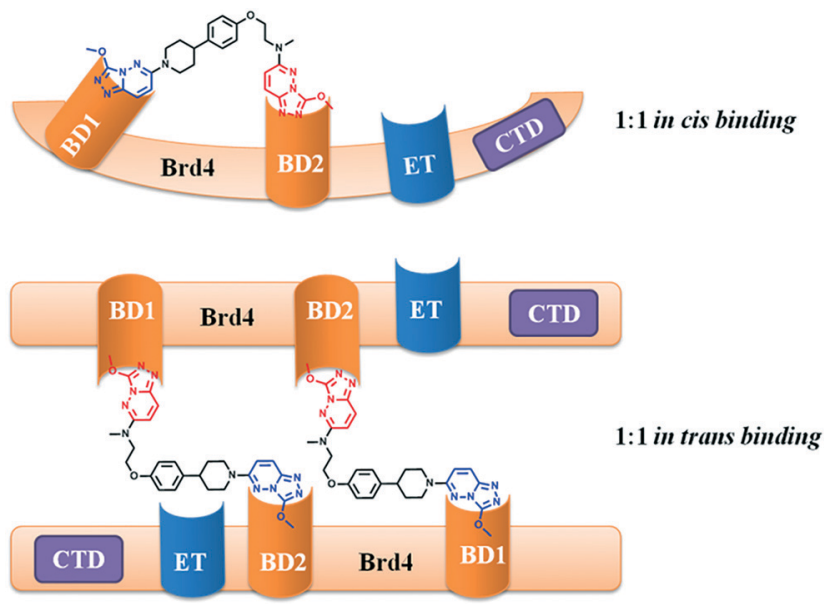

Fig. 16 Binding modes for bivalent Brd4 inhibitor 88 .

cancer cells than less sensitive cancer cells, consistent with its marked Brd4 inhibition. The cocrystal structure of Brd4(1) with compound 87 revealed that compound 87 could remarkably induce dimerization of two Brd4(1) by spanning both the acetyl-lysine binding pocket via the triazolopyridazine motif and the piperazinone group.

Further modification of compound 87 by changing the piperazinone group or chloro-substituted triazolopyridazine with a methoxy-substituted triazolopyridazine, a more potent acetyl-lysine pocket binding scaffold, gave compounds 88 and 89 (AZD5153), respectively. ${ }^{93}$ Compound 88 was identified as the most potent Brd4 inhibitor reported to date with $\mathrm{p} K_{\mathrm{d}}$ values of 8.1 and 7.3 against $\operatorname{Brd4} 4(1)$ and $\operatorname{Brd} 4(2)$, respectively. It was also found that compound 88 showed few offtarget effects on cellular receptors and ion channels, more than 100 of which were tested. The increased Brd4 inhibition potency was reflected in its cellular activity; compound $\mathbf{8 8}$ displayed highly potent antiproliferation activity against both MV4-11 and MM.1S cells with a $\mathrm{pIC}_{50}$ of 9.5, which was 1000fold more potent than that of I-BET762. The therapeutic advantages of bivalent Brd4 inhibition by compound 88 was also evidenced by the near-complete cell killing in RS4-11 cancer cells, compared to I-BET762 with no full inhibition at even higher concentrations. Compound $\mathbf{8 8}$ was proved to be more significant and sustained in suppressing the c-Myc expression, which might be responsible for its enhanced antiproliferation activity.

Chen's group reported the anticancer effects of AZD5153 against hematologic malignancies. AZD5153 potently inhibited
Brd4 with $\mathrm{IC}_{50}$ values of $5 \mathrm{nM}$ against full-length $\mathrm{Brd} 4$ and 1.6 $\mu \mathrm{M}$ against Brd4(1). AZD5153 was more potent than the monovalent inhibitor I-BET762 in down-regulating c-Myc, with a c-Myc protein modulation $\mathrm{IC}_{50}$ of $5.4 \mathrm{nM}$ for AZD5153 compared with an $\mathrm{IC}_{50}$ of $329 \mathrm{nM}$ for I-BET762. AZD5153 displayed an excellent pharmacokinetic profile and tumor growth inhibition in xenograft studies. In a xenograft model of MV4-11 cancer cells, daily treatment with $1 \mathrm{mg} \mathrm{kg}^{-1}$ AZD5153 gave a TGI of $72 \%$, while $5 \mathrm{mg} \mathrm{kg}^{-1}$ daily oral doses of AZD5153 led to tumor repression. ${ }^{94}$ AZD5153 is now in a phase I clinical trial by AstraZeneca for treatment of malignant solid tumors and lymphoma. ${ }^{95}$

Compound 88 engaged two Brd4(1)s concurrently in a fashion similar to that observed with compound 87 and reduced a Brd4(1) dimer confirmed by X-ray. A variety of biophysical experiments including NMR spectroscopy, analytical ultracentrifugation, and small-angle X-ray scattering were performed to elucidate the binding mode of $\mathbf{8 8}$ with fulllength Brd4 in cells. The results showed that compound $\mathbf{8 8}$ simultaneously bound both BD1 and BD2 of a single Brd4 in cis binding fashion and brought the two Brds into close proximity via folding the Brd4 protein (Fig. 16).

Bradner et al. described a series of bivalent Brd4 inhibitors by tethering two (+)-JQ1 molecules via a variable-length polyethylene glycol linker. Among them, compound MT1 (90) was identified as a more potent Brd4 bivalent inhibitor with improvement of exposure time and PK properties in vivo compared to (+)-JQ1 (Fig. 17). ${ }^{96}$ Size-exclusion chromatography (SEC) with bromodomain mutant experiments supported that one MT1 molecule simultaneously inhibited both BD1 and BD2 of Brd4 in cis binding mode, as observed with compound 88. In cellular assays, $100 \mathrm{nM}$ MT1 remarkably and rapidly depleted c-Myc protein, up-regulated HEXIM, and showed a 10-fold higher potency in reducing apoptosis in MV4-11 cells than the corresponding monovalent inhibitor, (+)-JQ1. Mouse studies exhibited that a half-equivalence of MT1 significantly delayed leukemia progression in an aggressive disseminated leukemia mouse model (mCherry + , luciferase+ MV4-11) compared to (+)-JQ1. The findings of SEC, ITC and nanomaterial-based proximity assays supported that the improved antitumor activity of MT1 was associated with its ability to dimerize Brds.

\section{Brd4 degraders}

While Brd4 inhibitors have demonstrated their promising therapeutic potential in a variety of $\mathrm{c}-M y c$-driven malignancies,

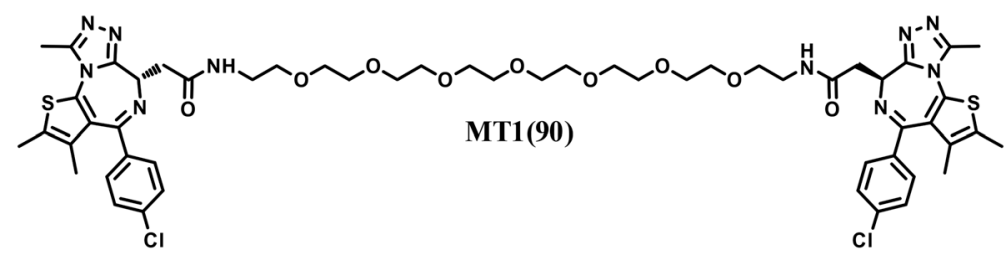

Fig. 17 The structure of bivalent Brd4 inhibitor MT1. 
several recent studies showed that Brd4 inhibitors led to significant compensatory accumulation of $\mathrm{Brd} 4$ protein in several cancers including Burkitt's lymphoma, lung cancer and prostate cancer, which may account for their inefficient $c$-Myc suppression, modest apoptotic induction and antiproliferative activity. ${ }^{97,98}$ Moreover, drug resistance against triazoloazepinebased Brd4 inhibitors I-BET762 and (+)-JQ1 has been described. ${ }^{99}$

In addition to target protein inhibition, selective induced target protein degradation was emerging as a novel drug discovery strategy. ${ }^{100,101}$ One promising approach to degrade protein is to design proteolysis-targeting chimeras (PROTACs), which has draw extensive attention from medicinal chemists and pharmaceutical firms. ${ }^{100,102-105}$ PROTAC, initially proposed 15 years ago by Deshaies et al., ${ }^{106}$ was a heterofunctional bispecific small molecule. It comprises three components: a target protein-specific ligand, an E3 ubiquitin ligase binder and a linker that couples these two functionalities. The PROTACs forms a ternary complex by binding to both the target protein and a component of E3 ubiquitin ligase in a spatially favorable presentation to promote the target protein ubiquitination by the E3 ligases, thereby eliciting its ubiquitination and subsequent proteasomal degradation (Fig. 18). ${ }^{107,108}$

Theoretically, degradation of oncoproteins by PROTACs exhibited potential advantages over protein inhibition in cancer treatment. Firstly, removal of the entire protein is expected to be more effective compared to inhibiting an individual activity site, which leaves other parts and domains of the proteins still functional; secondly, PROTACs could act catalytically to degrade superstoichiometric amounts of the target protein; thirdly, "undruggable" proteins including transcription factors could be targeted by PROTACs. ${ }^{109,110}$

PROTACs have recently been used to degrade a variety of proteins including tyrosine kinases, ${ }^{111}$ estrogen receptor $\alpha,{ }^{112}$ CDK9, ${ }^{113}$ Bcr-Abl $^{114,115}$ and so on. Considering the therapeutic potential of epigenetic regulator $\mathrm{Brd} 4$ in cancers and compensatory protein up-regulation often observed upon Brd4 inhibition, several groups sought to utilize PROTACs to degrade
Brd4 to treat cancers. Recently reported Brd4-targeted PROTACs were mainly designed based on thalidomide derivatives (91-93) identified as small ligands of cereblon (CRBN), a component of the CRL4 ${ }^{\text {CRBN }}$ E3 ligases, ${ }^{116}$ and VHL-2 (94) and VH-032 (95), two high-affinity ligands of the CRL2 ${ }^{\mathrm{VHL}}$ E3 complex (Table 2) (Fig. 19). ${ }^{117,118}$

\subsection{CRL4 ${ }^{\text {CRBN }}$ E3-based Brd4 degraders}

CRL4 ${ }^{\text {CRBN }}$ E3-based PROTACs targeting Brd4 were synthesized by connecting thalidomide derivatives to various $\operatorname{Brd} 4$ small-molecule inhibitors via different linkers (Fig. 20). The aryl ring of thalidomide derivatives and the carboxyl scaffold on Brd4 inhibitors can tolerate chemical substitution and so were chosen as suitable connecting points for a linker.

Winter et al. demonstrated a small-molecule CRL4 ${ }^{\text {CRBN }}$ E3-based degrader compound 96 (dBET1), which consisted of a Brd4 inhibitor (+)-JQ1 linked to a thalidomide derivative, which binds CRBN. ${ }^{119}$ On treatment with the MV4-11 cell line for 2 hours at a concentration as low as $100 \mathrm{nM}$, dBET1 could entirely degrade Brd4 and significantly reduced its transcriptional target c-Myc, with minimal off-target degradation. Degradation of Brd4 by dBET1 induced a more potent and superior inhibitory effect than (+)-JQ1 against MV4-11 cells, DHL4 lymphoma cells and primary blasts from patients with leukemia. The therapeutic opportunity of ABET1 in vivo was evaluated in a murine hind-limb xenograft model of human MV411 leukemia cells and an aggressive disseminated leukemia mouse model (mCherry+ MV4-11). In the AML model, daily treatment with dBET1 significantly attenuated tumor progression and decreased tumor weight in two weeks, together with Brd4 degradation and c-Myc down-regulation. Notably, in the disseminated model, dBET1 treatment caused a greater decrease in leukemic burden in bone marrow than did (+)-JQ1.

Concurrent with Winter's study, Crews et al. reported another small-molecule CRL4 ${ }^{\text {CRBN }}$ E3-based PROTAC ARV-825 (97), which was capable of degrading Brd4 rapidly at picomolar potencies in Burkitt's lymphoma cells. ${ }^{97}$ ARV-825 was synthesized by connecting a small-molecule Brd4 inhibitor (OTX015)

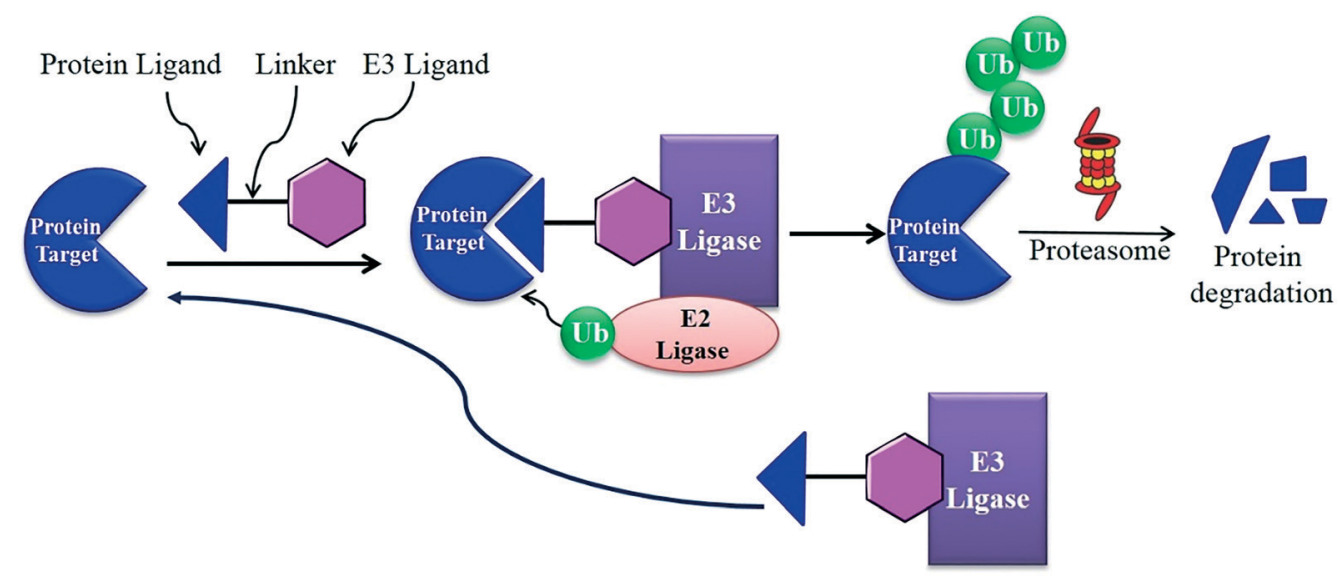

Fig. 18 Mechanism of protein degradation by PROTACs. 
Table 2 Overview of small-molecule Brd4 degraders

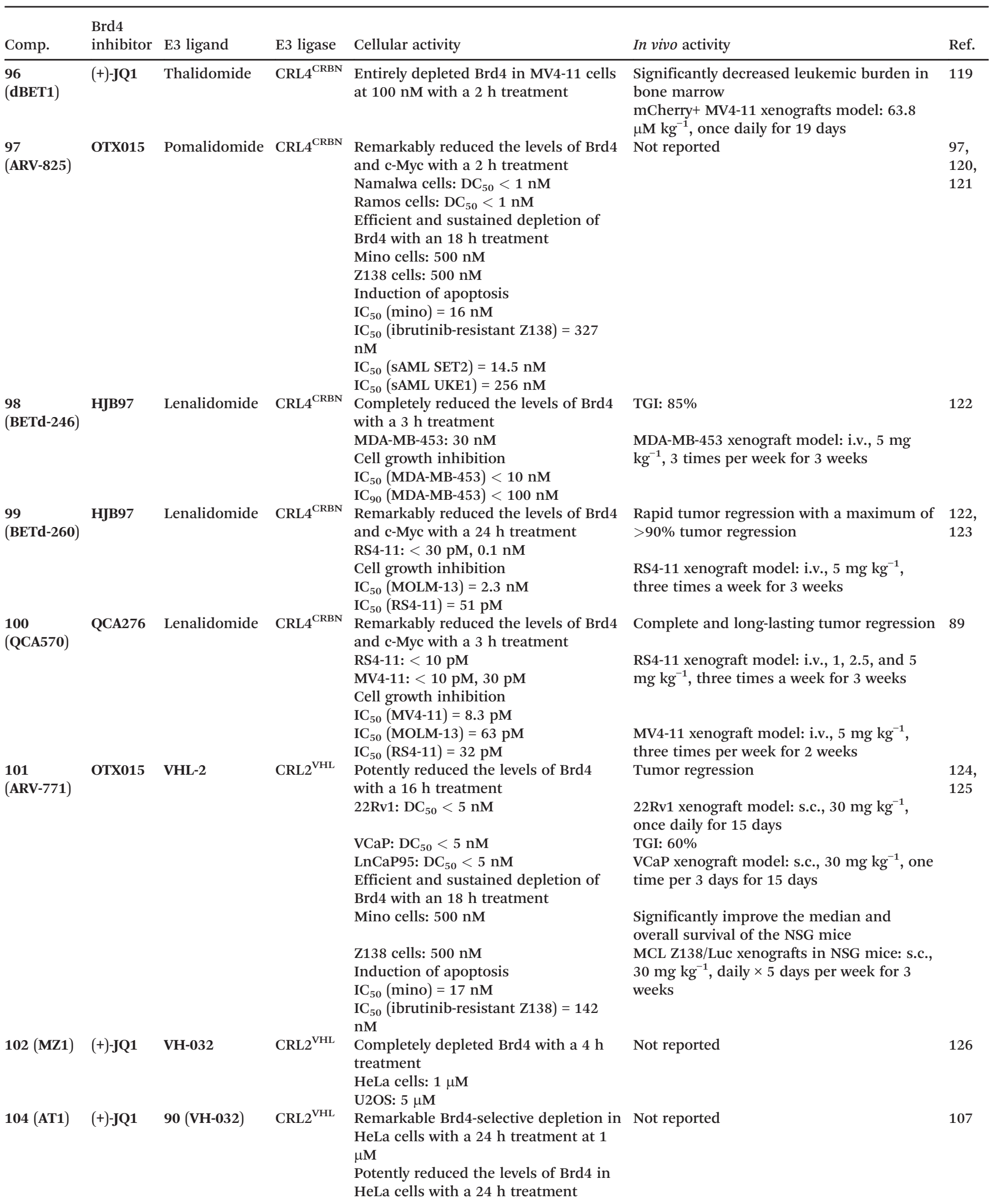


Table 2 (continued)

\begin{tabular}{|c|c|c|c|c|c|c|}
\hline $\begin{array}{l}106 \\
\text { (MZP-54) }\end{array}$ & I-BET726 & 90 (VH-032) & $\mathrm{CRL} 2^{\mathrm{VHL}}$ & $\begin{array}{l}\mathrm{pDC}_{50}(\text { Brd4 short })=8.0 \\
\text { pDC }_{50}(\text { Brd4 long })=7.6 \\
\text { Cell growth inhibition } \\
\text { pEC }_{50}(\mathrm{MV} 4-11)=7.31 \\
\text { pEC }_{50}(\text { HeLa })=6.57\end{array}$ & Not reported & 127 \\
\hline
\end{tabular}

to pomalidomide via a flexible polyethylene glycol linker. Treatment of Burkitt's lymphoma cells with ARV-825 led to 50\% Brd4 protein degradation within 2 hours, with a $\mathrm{DC}_{50}(50 \%$ of maximum degradation) below $1 \mathrm{nM}$. Given that the $K_{\mathrm{d}}$ values of OTX015 and pomalidomide to their respective targets, Brd4 and cereblon, were $10 \mathrm{nM}$ and $3 \mu \mathrm{M}$, respectively, ARV-825 showed sub-stoichiometric characteristics in degrading Brd4. ${ }^{120}$ In comparison to the Brd4 inhibitors (+)-JQ1 and OTX015, ARV-825 provided a more prolonged and pronounced suppression of c-Myc levels even at lower concentrations and showed no Brd4 accumulation which was associated with Brd4 inhibition. This sustained suppression of c-Myc translated into superior antiproliferative and apoptotic effects of the ARV-825 against Burkitt's lymphoma cells compared with the Brd4 inhibitors. They also found that ARV-825 was more profound and longer-lasting than OTX015 in depleting Brd4, c-Myc, CDK4/6, JAK2, pSTAT3/5, PIM1 and Bcl-xL in cultured and patientderived $\mathrm{CD}^{+} 4^{+}$post-MPN sAML cells, including those expressing JAK2-V617F and mutant TP5, consistent with higher ARV825-induced apoptosis and lethality in SAML cells. ${ }^{121}$

BETd-246 (98) was developed by Wang's group using an azacarbazole-containing Brd4 inhibitor HJB97 coupled to lenalidomide via a polyethylene glycol linker. ${ }^{122}$ The majority of Brd4 was depleted after treatment with BETd-246 for three hours at 10 to $30 \mathrm{nM}$ in several triple-negative breast cell lines. BETd-246 strongly suppressed the growth of 9 TNBC cell lines with $\mathrm{IC}_{50}<10 \mathrm{nM}$, and was 50 -fold more potent than HJB97. In both Washington Human in Mouse (WHIM) and MDA-MB-453 xenograft models, BETd-246 achieved significant antitumor activity and induced partial tumor regression at well-tolerated dose schedules. However, BETd-246

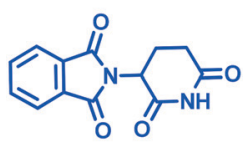

Thalidomide (91)

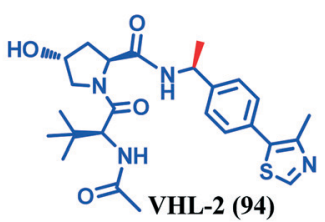

Fig. 19 Reported $\mathrm{CRL} 4^{\mathrm{CRBN}} \mathrm{E3}$ and $\mathrm{CRL} 2^{\mathrm{VHL}} \mathrm{E3}$ small-molecule ligands. showed very limited or no antitumor activity in MDA-M-231 and MDA-MB-468 xenograft models, respectively, due to limited drug exposure in both models.

BETd-260 (99) was generated by further structure optimization of BETd-246. ${ }^{123}$ BETd-260 showed a more potent antiproliferative activity than BETd-246 in TNBC cells, and more importantly, BETd-260 exhibited a much higher drug exposure in both MDA-MB-231 and MDA-MB-468 xenograft models and exerted a much stronger antitumor activity than BETd-246 without inducing observable toxic effects. ${ }^{122}$ BETd260 was capable of effectively reducing the level of Brd4 protein at concentrations as low as $30 \mathrm{pM}$ with a 24 hour treatment in the RS4-11 leukemia cell line, accompanied by strong down-regulation of c-Myc protein, while HJB97 showed no effect on the level of Brd4 proteins even at $1 \mu \mathrm{M}$. BETd260 significantly inhibited RS4-11 cell line and MOLM-13 cell line proliferation with $\mathrm{IC}_{50}$ values of $51 \mathrm{pM}$ and $2.3 \mathrm{nM}$, respectively. In vivo, treatment of the RS4-11 xenograft model with BETd-260 induced rapid tumor regression with a maximum of $>90 \%$ regression observed.

More recently, Wang's group reported an exceptionally potent small-molecule BET degrader QCA570 (100), which was synthesized using a novel [1,4] oxazepine-based BET inhibitor developed by Wang's group and known as cereblon ligand. ${ }^{89}$ After $3 \mathrm{~h}$ of treatment, QCA570 was capable of effectively reducing the levels of Brd4 and c-Myc at concentrations as low as $10 \mathrm{pM}$ in the RS4-11 cell line and $30 \mathrm{pM}$ in the MV4-11 cell line, while the corresponding Brd4 inhibitor failed to abate the levels of Brd4 and c-Myc at a concentration of $10 \mu \mathrm{M}$. Consistent with its extraordinary ability to suppress Brd4, QCA570 showed significant potency in inhibition of cell growth in MV4-11, MOLM-13, and RS4-11 cell lines with $\mathrm{IC}_{50}$ values of 8.3, 62, and $32 \mathrm{pM}$, respectively. A direct comparison of cell growth inhibitory potency in these three leukemia cell lines between QCA570 and previously published Brd4 degraders including dBET1, ARV-825 and ARV-771 was performed. The results demonstrated that QCA570 was the most potent and efficacious Brd4 degrader to date. Significantly, in both the MV411 and RS4-11 acute leukemia xenograft models, QCA570 achieved complete and long-lasting tumor regression at $5 \mathrm{mg}$ $\mathrm{kg}^{-1}$ without apparent toxicity (Fig. 21).

\subsection{CRL2 ${ }^{\mathrm{VHL}}$ E3-based Brd4 degraders}

Inspection of VHL and its ligand crystal structures showed that the methyl group of the terminal acetyl groups in compounds 


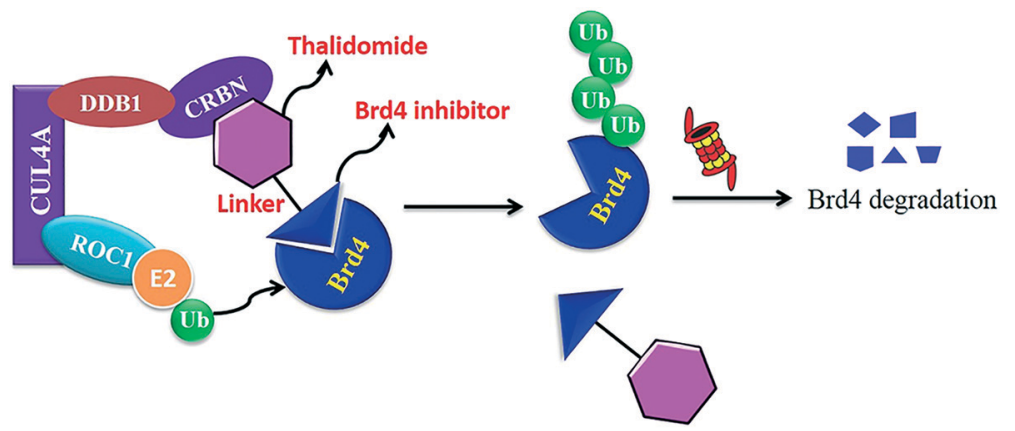

Fig. 20 Mechanism of Brd4 degradation by CRL4 ${ }^{\text {CRBN }}$ E3-based Brd4 degraders.<smiles>Cc1ccc(C2=N[C@@H](CC(=O)NCCCNC(=O)COc3cccc4c3C(=O)N(C3CCC(=O)NC3=O)C4=O)c3nnc(C)n32)cc1</smiles><smiles></smiles><smiles>CCn1nc(C2CC2)cc1Nc1nc(C(=O)NCCCOCCOCCOCCCNc2cccc3c2CN(C2CCC(=O)NC2=O)C3=O)nc2[nH]c3cc(-c4c(C)noc4C)ccc3c12</smiles>

BETd-246 (98)<smiles>CCn1cc(C2CC2)nc1Nc1nc(C(=O)NCCCCCCc2cccc3c2CN(C2CCC(=O)NC2=O)C3=O)nc2[nH]c3cc(-c4c(C)noc4C)c(OC)cc3c12</smiles>

BETd-260 (99)

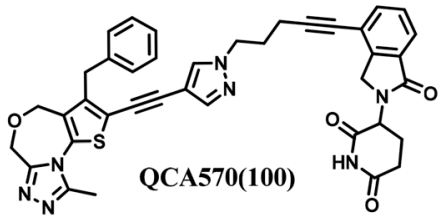

Fig. 21 Reported Brd4 degraders based on CRL4 ${ }^{\text {CRBN }}$ E3 ligase.

VHL-2 and VH-032 was solvent exposed, indicating that it could provide a suitable connecting point for a linker. By conjugating the terminal acetyl groups of VHL-2 or VH-032 with various Brd4 inhibitors through different linkers, CRL2 ${ }^{\mathrm{VHL}}$ E3-based Brd4 degraders were obtained (Fig. 22).

ARV-771 (101) is a VHL-based PROTAC using OTX015 for the BET inhibitor portion and VHL-2 as a ligand for the VHL
E3 ligase. ${ }^{124}$ ARV-771 specifically degraded Brd4 as well as $\operatorname{Brd} 2$ and $\mathrm{Brd} 3$ with a $\mathrm{DC}_{50}$ of $<5 \mathrm{nM}$ and led to the depletion of c-Myc protein with an $\mathrm{IC}_{50}<1 \mathrm{nM}$ in several cellular models of castration-resistant prostate cancer. In addition, despite possessing $K_{\mathrm{d}}$ values comparable with those of the (+)-JQ1, ARV-771 demonstrated a more than 10 times higher efficacy in decreasing c-Myc levels. This strongly supports

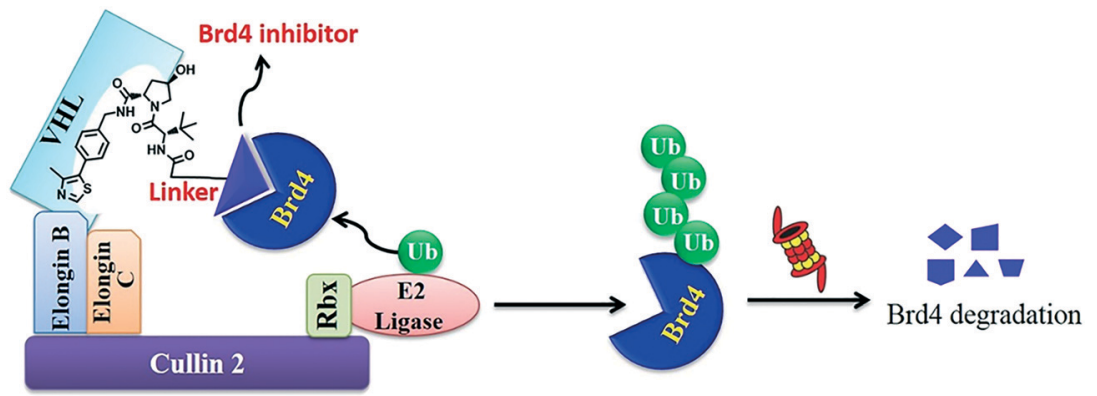

Fig. 22 Mechanism of Brd4 degradation by $\mathrm{CRL} 2^{\mathrm{VHL}} \mathrm{E} 3$-based Brd4 degraders. 

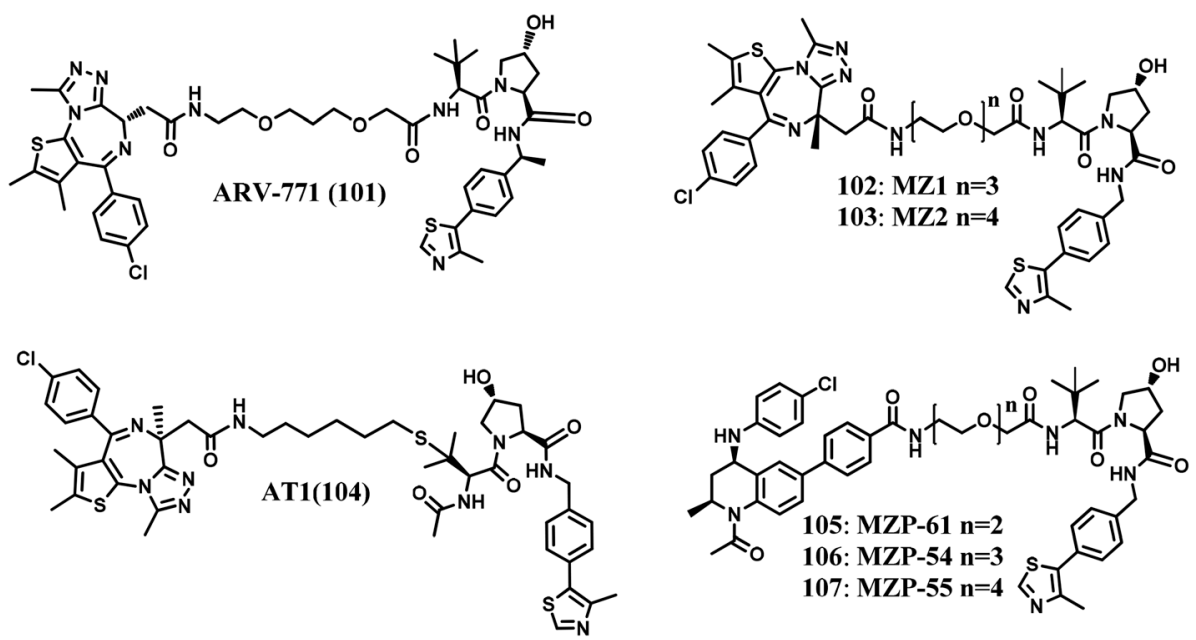

Fig. 23 Reported Brd4 degraders based on CRL2 ${ }^{\mathrm{VHL}} \mathrm{E} 3$ ligase.

that ARV-771 behaved catalytically in degrading Brd4, consistent with previous findings by Winter et al. and Crews et al. ${ }^{119,120}$ ARV-771 showed significant antiproliferative activity towards prostate cancer cells with 10- to 500-fold higher potency than the inhibitors (+)-JQ1 or OTX015, in line with its robust effects on apoptotic induction. In vivo experiments indicated that ARV-771, rather than inhibitor OTX015, effectively attenuated Brd4 and c-Myc levels and suppressed tumor growth and, more notably, induced partial tumor regression in a 22Rv1 xenograft model. ARV-771 also showed superior tumor suppression and induced greater survival improvement than OTX015 in immune-depleted mice engrafted with ibrutinib-resistant MCL cells. ${ }^{125}$

Ciulli and colleagues developed several PROTACs using (+)-JQ1 and VH-032, a high-affinity ligand that had been designed against the VHL E3 ligase. ${ }^{126}$ Treatment with MZ1 (102), the most potent compound, for $24 \mathrm{~h}$ at a concentration of $1 \mu \mathrm{M}$ completely depleted Brd4 proteins in HeLa cells, and no protein could be detected even after $48 \mathrm{~h}$, indicating that MZ1 was a powerful and long-lasting Brd4 degrader. Interestingly, despite (+)-JQ1 showing no selectivity for individual BET family members and MZ1 having comparable affinities to BET bromodomains, MZ1 could induce potent and preferential depletion of Brd4 over its homologues Brd2 and Brd3 at suitable concentrations in both HeLa cells and U2OS osteosarcoma cells, which partly accounted for the different protein depletion profile and pharmacological response between MZ1 and (+)-JQ1.

Recently, the crystal structure of the VHL E3-MZ1-Brd4 ternary complex and its impact on target degradation selectivity was elucidated by Ciulli et al. According to their work, AT1 (103) was synthesized by attaching (+)-JQ1 to the tert-Leu group of VHL ligand via a short linker, which was different from other VHL-based PROTACs. Treatment with $1 \mu \mathrm{M}$ AT1 for $24 \mathrm{~h}$ in all tested cancer cells depleted most of the Brd4, while the decrease of Brd2 and Brd3 as well as other 5671 detected proteins was negligible. This result suggested that AT1 exhibited a more remarkable selectivity in depleting Brd4 than MZ1. ${ }^{107}$
Most recently, Ciulli's group has reported three novel VHLrecruiting PROTACs, MZP-61 (105), MZP-54 (106) and MZP-55 (107), which were derived from a potent tetrahydroquinolinebased Brd4 inhibitor, I-BET726. ${ }^{127}$ MZP-54 proved to be the most powerful degrader, which was capable of inducing marked depletion of both BET and c-Myc proteins concentration-dependently in HeLa cells with a certain degree of selectivity for Brd4 and Brd3 over Brd2. However, despite IBET726 $\left(K_{\mathrm{d}}=4 \mathrm{nM}\right)$ being a more potent Brd4 inhibitor than $(+)-J Q 1\left(K_{\mathrm{d}}=100 \mathrm{nM}\right)$, a direct comparison showed that MZP54 was a less powerful Brd4 degrader than MZ1 due to negative cooperativities of ternary complex formation confirmed by ITC assay. Given being negatively cooperative, MZP-54 still effectively degraded Brd4 at nanomolar concentrations and showed remarkable antiproliferative activity in two tested cell lines, suggesting that substoichiometric catalytic degradation was powerful (Fig. 23).

\section{Conclusion}

Over the past decade, researchers have identified the cellular functions of BET proteins and their important roles in the development of many malignancies and other diseases including inflammation, HIV infection, and cardiovascular diseases. Among them, Brd4 is the most extensively studied member. Brd4 inhibitors with various scaffolds are being explored as therapeutic agents in numerous hematopoietic and solid tumor types, and some of them have entered into human clinical trials. Despite the exciting results of preliminary clinical trials using Brd4 inhibitors in malignancies, there are issues to resolve. Most of the reported $\mathrm{Brd} 4$ inhibitors bind non-selectively to BD1 and BD2 and also show low selectivity for individual BET family members. BET family members have different downstream gene regulatory profiles, and pan-BET inhibition makes an impact on numerous transcriptional pathways and leads to side effects, which has been observed in clinical trials of compound OTX015. ${ }^{128}$ Thus, significant efforts are urgently needed to develop Brd4 inhibitors 
with high specificity and affinity. Moreover, drug resistance against triazoloazepine Brd4 inhibitors has been reported. ${ }^{99}$ Considering the dominant position of triazoloazepine-based Brd4 inhibitors in clinical trials, novel Brd4 inhibitors with different chemical chemotypes deserve to be explored to address this issue as well as to elucidate the resistance mechanisms. Bivalent Brd4 inhibitors show profoundly enhanced potency than the parent monovalent inhibitor and may provide a new strategy for overcoming drug resistance. However, the bivalent Brd4 inhibitors reported now are mainly achieved by linking two monovalent inhibitors with a flexible linker, causing a large molecular weight and compromised drug-likeness; thus, there exists a large chemical space to develop structurally diverse bivalent Brd4 inhibitors.

In addition to functional inhibition by small molecules, Brd4 has been successfully targeted for degradation using PROTACs. Several PROTACs selectively and substoichiometrically degraded Brd4 and demonstrated a more potent antitumor activity than the corresponding Brd4 inhibitors. Albeit PROTAC-induced Brd4 degradation has achieved impressive efficacy in several mouse models of cancer, the clinical potential of this technology remains to be explored. Challenges, including unfavorable physicochemical properties and low bioavailability owing to their relatively large molecular mass and scarce small E3 ligands, must be overcome in order to advance PROTACs into the clinic.

Overall, both traditional small-molecule $\operatorname{Brd} 4$ inhibitors and newly-developed Brd4 degraders have shown promising results in various human cancers. There is great hope that with sustained efforts on the drug discovery of Brd4, novel anticancer drugs targeting Brd4 will be achieved in the near future.

\section{List of abbreviations}

Brd4(1) Bromodomain 1 of Brd4

Brd4(2) Bromodomain 2 of Brd4

$\mathrm{IC}_{50} \quad$ Half-maximal inhibitory concentration

EC $_{50} \quad$ Half-maximal effective concentration

$\mathrm{GI}_{50} \quad$ Half-maximal growth inhibitory concentration

TGI Tumor growth inhibition

$K_{\mathrm{d}} \quad$ Dissociation constant

$K_{\mathrm{i}} \quad$ Inhibition constant

$T_{1 / 2} \quad$ Elimination half-life

$F \quad$ Bioavailability

Q.D. Once a day

\section{Conflicts of interest}

There are no conflicts of interest to declare.

\section{Acknowledgements}

This work was supported by the National Natural Science Foundation of China (Project No. 81402793 and U1704184 for Y.-C. D., Project No. 81430085 and 81773562 for H.-M. L., and Project No. 81703326 for B. Y.), the Key Scientific Research
Project for Higher Education by the Department of Education of Henan Educational Committee (Project No.18B350009 for H.-M. L.), the National Key Research Program of Proteins (Project No. 2016YFA0501800 for H.-M. L.), and the Scientific Program of Henan Province (Project No. 182102310123 for H.M. L.). This project was funded by the China Postdoctoral Science Foundation (Project No. 2018M630840 for B. Y.).

\section{References}

1 S. Y. R. Ronen Marmorstein, Curr. Opin. Genet. Dev., 2001, 11, 155-161.

2 T. Jenuwein and C. D. Allis, Science, 2001, 293, 1074-1080.

3 N. S. S. Jaiprakash, N. Sangshett, M. H. G. Dehghan and D. B. Shinde, Mini-Rev. Med. Chem., 2013, 13, 1005-1026.

4 L. Zeng and M. M. Zhou, FEBS Lett., 2002, 124-128.

5 E. Ferri, C. Petosa and C. E. McKenna, Biochem. Pharmacol., 2016, 106, 1-18.

6 P. Filippakopoulos, S. Picaud, M. Mangos, T. Keates, J. P. Lambert, D. Barsyte-Lovejoy, I. Felletar, R. Volkmer, S. Muller, T. Pawson, A. C. Gingras, C. H. Arrowsmith and S. Knapp, Cell, 2012, 149, 214-231.

7 S. Y. Wu and C. M. Chiang, J. Biol. Chem., 2007, 282, 13141-13145.

8 F. Vollmuth, W. Blankenfeldt and M. Geyer, J. Biol. Chem., 2009, 284, 36547-36556.

9 C. W. Chung, H. Coste, J. H. White, O. Mirguet, J. Wilde, R. L. Gosmini, C. Delves, S. M. Magny, R. Woodward, S. A. Hughes, E. V. Boursier, H. Flynn, A. M. Bouillot, P. Bamborough, J. M. Brusq, F. J. Gellibert, E. J. Jones, A. M. Riou, P. Homes, S. L. Martin, I. J. Uings, J. Toum, C. A. Clement, A. B. Boullay, R. L. Grimley, F. M. Blandel, R. K. Prinjha, K. Lee, J. Kirilovsky and E. Nicodeme, J. Med. Chem., 2011, 54, 3827-3838.

10 Z. Yang, J. H. Yik, R. Chen, N. He, M. K. Jang, K. Ozato and Q. Zhou, Mol. Cell, 2005, 19, 535-545.

11 J. E. Delmore, G. C. Issa, M. E. Lemieux, P. B. Rahl, J. Shi, H. M. Jacobs, E. Kastritis, T. Gilpatrick, R. M. Paranal, J. Qi, M. Chesi, A. C. Schinzel, M. R. McKeown, T. P. Heffernan, C. R. Vakoc, P. L. Bergsagel, I. M. Ghobrial, P. G. Richardson, R. A. Young, W. C. Hahn, K. C. Anderson, A. L. Kung, J. E. Bradner and C. S. Mitsiades, Cell, 2011, 146, 904-917.

12 J. Zuber, J. Shi, E. Wang, A. R. Rappaport, H. Herrmann, E. A. Sison, D. Magoon, J. Qi, K. Blatt, M. Wunderlich, M. J. Taylor, C. Johns, A. Chicas, J. C. Mulloy, S. C. Kogan, P. Brown, P. Valent, J. E. Bradner, S. W. Lowe and C. R. Vakoc, Nature, 2011, 478, 524-528.

13 P. Valent and J. Zuber, Cell Cycle, 2014, 13, 689-690.

14 J. Alsarraj and K. W. Hunter, Int. J. Breast Cancer, 2012, 2012, 670632.

15 N. P. Crawford, J. Alsarraj, L. Lukes, R. C. Walker, J. S. Officewala, H. H. Yang, M. P. Lee, K. Ozato and K. W. Hunter, Proc. Natl. Acad. Sci. U. S. A., 2008, 105, 6380-6385.

16 Q. Feng, Z. Zhang, M. J. Shea, C. J. Creighton, C. Coarfa, S. G. Hilsenbeck, R. Lanz, B. He, L. Wang, X. Fu, A. 
Nardone, Y. Song, J. Bradner, N. Mitsiades, C. S. Mitsiades, C. K. Osborne, R. Schiff and B. W. O'Malley, Cell Res., 2014, 24, 809-819.

17 Y. F. Liao, Y. B. Wu, X. Long, S. Q. Zhu, C. Jin, J. J. Xu and J. Y. Ding, Oncotarget, 2016, 7, 9491-9500.

18 M. F. Segura, B. Fontanals-Cirera, A. Gaziel-Sovran, M. V. Guijarro, D. Hanniford, G. Zhang, P. Gonzalez-Gomez, M. Morante, L. Jubierre, W. Zhang, F. Darvishian, M. Ohlmeyer, I. Osman, M. M. Zhou and E. Hernando, Cancer Res., 2013, 73, 6264-6276.

19 C. Pastori, M. Daniel, C. Penas, C. H. Volmar, A. L. Johnstone, S. P. Brothers, R. M. Graham, B. Allen, J. N. Sarkaria, R. J. Komotar, C. Wahlestedt and N. G. Ayad, Epigenetics, 2014, 9, 611-620.

20 I. A. Asangani, V. L. Dommeti, X. Wang, R. Malik, M. Cieslik, R. Yang, J. Escara-Wilke, K. Wilder-Romans, S. Dhanireddy, C. Engelke, M. K. Iyer, X. Jing, Y. M. Wu, X. Cao, Z. S. Qin, S. Wang, F. Y. Feng and A. M. Chinnaiyan, Nature, 2014, 510, 278-282.

21 P. Filippakopoulos and S. Knapp, Nat. Rev. Drug Discovery, 2014, 13, 337-356.

22 M. Jung, K. A. Gelato, A. Fernandez-Montalvan, S. Siegel and B. Haendler, Epigenomics, 2015, 7, 487-501.

23 Z. Liu, P. Wang, H. Chen, E. A. Wold, B. Tian, A. R. Brasier and J. Zhou, J. Med. Chem., 2017, 60, 4533-4558.

24 F. Zhang and S. Ma, Curr. Drug Targets, 2018, 19, 1148-1165.

25 I. Ali, G. Choi and K. Lee, Recent Pat. Anti-Cancer Drug Discovery, 2017, 12, 340-364.

26 J. A. Mertz, A. R. Conery, B. M. Bryant, P. Sandy, S. Balasubramanian, D. A. Mele, L. Bergeron and R. J. Sims, 3rd, Proc. Natl. Acad. Sci. U. S. A., 2011, 108, 16669-16674.

27 C. Berthon, E. Raffoux, X. Thomas, N. Vey, C. Gomez-Roca, K. Yee, D. C. Taussig, K. Rezai, C. Roumier, P. Herait, C. Kahatt, B. Quesnel, M. Michallet, C. Recher, F. Lokiec, C. Preudhomme and H. Dombret, Lancet Haematol., 2016, 3, e186-e195.

28 A. Stathis, E. Zucca, M. Bekradda, C. Gomez-Roca, J. P. Delord, T. de La Motte Rouge, E. Uro-Coste, F. de Braud, G. Pelosi and C. A. French, Cancer Discovery, 2016, 6, 492-500.

29 M. Boi, E. Gaudio, P. Bonetti, I. Kwee, E. Bernasconi, C. Tarantelli, A. Rinaldi, M. Testoni, L. Cascione, M. Ponzoni, A. A. Mensah, A. Stathis, G. Stussi, M. E. Riveiro, P. Herait, G. Inghirami, E. Cvitkovic, E. Zucca and F. Bertoni, Clin. Cancer Res., 2015, 21, 1628-1638.

30 Clinical-Trials.gov, https://clinicaltrials.gov/ct2/show/ NCT02308761?term=TEN-010\&rank=1, December 11, 2017.

31 S. B. Landau and M. Kagey, WO2016069578, 2016.

32 N. Schmees, J. Kuhnke, B. Haendler, P. Lienau, A. E. Fernandez-Montalvan, P. Lejeune, S. Siegel and W. Scott, WO2013030150, 2013.

33 J. Endo, H. Hikawa, M. Hamada, S. Ishibuchi, N. Fujie, N. Sugiyama, M. Tanaka, H. Kobayashi, K. Sugahara, K. Oshita, K. Iwata, S. Ooike, M. Murata, H. Sumichika, K. Chiba and K. Adachi, Bioorg. Med. Chem. Lett., 2016, 26, 1365-1370.
34 O. Mirguet, R. Gosmini, J. Toum, C. A. Clement, M. Barnathan, J. M. Brusq, J. E. Mordaunt, R. M. Grimes, M. Crowe, O. Pineau, M. Ajakane, A. Daugan, P. Jeffrey, L. Cutler, A. C. Haynes, N. N. Smithers, C. W. Chung, P. Bamborough, I. J. Uings, A. Lewis, J. Witherington, N. Parr, R. K. Prinjha and E. Nicodeme, J. Med. Chem., 2013, 56, 7501-7515.

35 A. Chaidos, V. Caputo, K. Gouvedenou, B. Liu, I. Marigo, M. S. Chaudhry, A. Rotolo, D. F. Tough, N. N. Smithers, A. K. Bassil, T. D. Chapman, N. R. Harker, O. Barbash, P. Tummino, N. Al-Mahdi, A. C. Haynes, L. Cutler, B. Le, A. Rahemtulla, I. Roberts, M. Kleijnen, J. J. Witherington, N. J. Parr, R. K. Prinjha and A. Karadimitris, Blood, 2014, 123, 697-705.

36 Y. Zhao, C. Y. Yang and S. Wang, J. Med. Chem., 2013, 56, 7498-7500.

37 N. Schmees, J. Kuhnke, B. Haendler, R. Neuhaus, P. Lejeune, S. Siegel, M. Krüger, A. E. Fernandez-Montalvan, H. Künzer and D. Gallenkamp, WO2014048945A1, 2014.

38 N. Schmees, B. Buchmann, B. Haendler, R. Neuhaus, P. Lejeune, M. Krüger, A. E. Fernandez-Montalvan and H. Künzer, WO2014128070A1, 2014.

39 S. Hsiegel, S. Bäurle, A. Cleve, B. Haendler, A. M. Fernández-Montalván, U. Mönning, S. Krause, P. Lejeune, M. Busemann and J. Kuhnke, WO2014128067, 2014.

40 V. S. Gehling, M. C. Hewitt, R. G. Vaswani, Y. Leblanc, A. Cote, C. G. Nasveschuk, A. M. Taylor, J. C. Harmange, J. E. Audia, E. Pardo, S. Joshi, P. Sandy, J. A. Mertz, R. J. Sims, 3rd, L. Bergeron, B. M. Bryant, S. Bellon, F. Poy, H. Jayaram, R. Sankaranarayanan, S. Yellapantula, N. Bangalore Srinivasamurthy, S. Birudukota and B. K. Albrecht, ACS Med. Chem. Lett., 2013, 4, 835-840.

41 B. K. Albrecht, V. S. Gehling, M. C. Hewitt, R. G. Vaswani, A. Cote, Y. Leblanc, C. G. Nasveschuk, S. Bellon, L. Bergeron, R. Campbell, N. Cantone, M. R. Cooper, R. T. Cummings, H. Jayaram, S. Joshi, J. A. Mertz, A. Neiss, E. Normant, M. O'Meara, E. Pardo, F. Poy, P. Sandy, J. Supko, R. J. Sims, 3rd, J. C. Harmange, A. M. Taylor and J. E. Audia, J. Med. Chem., 2016, 59, 1330-1339.

42 M. C. Hewitt, Y. Leblanc, V. S. Gehling, R. G. Vaswani, A. Cote, C. G. Nasveschuk, A. M. Taylor, J. C. Harmange, J. E. Audia, E. Pardo, R. Cummings, S. Joshi, P. Sandy, J. A. Mertz, R. J. Sims, 3rd, L. Bergeron, B. M. Bryant, S. Bellon, F. Poy, H. Jayaram, Y. Tang and B. K. Albrecht, Bioorg. Med. Chem. Lett., 2015, 25, 1842-1848.

43 D. S. Hewings, M. Wang, M. Philpott, O. Fedorov, S. Uttarkar, P. Filippakopoulos, S. Picaud, C. Vuppusetty, B. Marsden, S. Knapp, S. J. Conway and T. D. Heightman, J. Med. Chem., 2011, 54, 6761-6770.

44 D. S. Hewings, O. Fedorov, P. Filippakopoulos, S. Martin, S. Picaud, A. Tumber, C. Wells, M. M. Olcina, K. Freeman, A. Gill, A. J. Ritchie, D. W. Sheppard, A. J. Russell, E. M. Hammond, S. Knapp, P. E. Brennan and S. J. Conway, J. Med. Chem., 2013, 56, 3217-3227.

45 P. Bamborough, H. Diallo, J. D. Goodacre, L. Gordon, A. Lewis, J. T. Seal, D. M. Wilson, M. D. Woodrow and C. W. Chung, J. Med. Chem., 2012, 55, 587-596. 
46 M. R. McKeown, D. L. Shaw, H. Fu, S. Liu, X. Xu, J. J. Marineau, Y. Huang, X. Zhang, D. L. Buckley, A. Kadam, Z. Zhang, S. C. Blacklow, J. Qi, W. Zhang and J. E. Bradner, J. Med. Chem., 2014, 57, 9019-9027.

47 O. Mirguet, Y. Lamotte, F. Donche, J. Toum, F. Gellibert, A. Bouillot, R. Gosmini, V. L. Nguyen, D. Delannee, J. Seal, F. Blandel, A. B. Boullay, E. Boursier, S. Martin, J. M. Brusq, G. Krysa, A. Riou, R. Tellier, A. Costaz, P. Huet, Y. Dudit, L. Trottet, J. Kirilovsky and E. Nicodeme, Bioorg. Med. Chem. Lett., 2012, 22, 2963-2967.

48 J. Seal, Y. Lamotte, F. Donche, A. Bouillot, O. Mirguet, F. Gellibert, E. Nicodeme, G. Krysa, J. Kirilovsky, S. Beinke, S. McCleary, I. Rioja, P. Bamborough, C. W. Chung, L. Gordon, T. Lewis, A. L. Walker, L. Cutler, D. Lugo, D. M. Wilson, J. Witherington, K. Lee and R. K. Prinjha, Bioorg. Med. Chem. Lett., 2012, 22, 2968-2972.

49 D. P. Slassi Abdelmalik, WO2016123709, 2016.

50 O. Mirguet, Y. Lamotte, C. W. Chung, P. Bamborough, D. Delannee, A. Bouillot, F. Gellibert, G. Krysa, A. Lewis, J. Witherington, P. Huet, Y. Dudit, L. Trottet and E. Nicodeme, ChemMedChem, 2014, 9, 580-589.

51 X. Ran, Y. Zhao, L. Liu, L. Bai, C. Y. Yang, B. Zhou, J. L. Meagher, K. Chinnaswamy, J. A. Stuckey and S. Wang, J. Med. Chem., 2015, 58, 4927-4939.

52 L. Wang, X. Wu, R. Wang, C. Yang, Z. Li, C. Wang, F. Zhang and P. Yang, Biol. Res., 2017, 50, 19.

53 H. G. Ozer, D. El-Gamal, B. Powell, Z. A. Hing, J. S. Blachly, B. Harrington, S. Mitchell, N. R. Grieselhuber, K. Williams, T. H. Lai, L. Alinari, R. A. Baiocchi, L. Brinton, E. Baskin, M. Cannon, L. Beaver, V. M. Goettl, D. M. Lucas, J. A. Woyach, D. Sampath, A. M. Lehman, L. Yu, J. Zhang, Y. Ma, Y. Zhang, W. Spevak, S. Shi, P. Severson, R. Shellooe, H. Carias, G. Tsang, K. Dong, T. Ewing, A. Marimuthu, C. Tantoy, J. Walters, L. Sanftner, H. Rezaei, M. Nespi, B. Matusow, G. Habets, P. Ibrahim, C. Zhang, E. A. Mathe, G. Bollag, J. C. Byrd and R. Lapalombella, Cancer Discovery, 2018, 8, 458-477.

54 B. Ren, C. Y. Zhou and H. Wang, WO2014173241, 2014.

55 P. C. C. Liu, X. S. M. Liu, M. C. Stubbs, T. Maduskuie, R. Sparks, N. Zolotarjova, J. Li, X. M. Wen, M. Favata, P. Feldman, A. Volgina, D. DiMatteo, R. Collins, N. Falahatpisheh, P. Polam, Y. Li, M. Covington, S. DiamondFosbenner, R. Wynn, T. Burn, K. Vaddi, S. Yeleswaram, A. P. Combs, W. Q. Yao, R. Huber, P. Scherle and G. Hollis, Cancer Res., 2015, 75, 3523.

56 D. Hay, O. Fedorov, P. Filippakopoulos, S. Martin, M. Philpott, S. Picaud, D. S. Hewings, S. Uttakar, T. D. Heightman, S. J. Conway, S. Knapp and P. E. Brennan, MedChemComm, 2013, 4, 140-144.

57 Y. Yang, L. Zhao, B. Xu, L. Yang, J. Zhang, H. Zhang and J. Zhou, Bioorg. Chem., 2016, 68, 236-244.

58 M. Zhang, Y. Zhang, M. Song, X. Xue, J. Wang, C. Wang, C. Zhang, C. Li, Q. Xiang, L. Zou, X. Wu, C. Wu, B. Dong, W. Xue, Y. Zhou, H. Chen, D. Wu, K. Ding and Y. Xu, J. Med. Chem., 2018, 61, 3037-3058.

59 L. Wang, J. K. Pratt, T. Soltwedel, G. S. Sheppard, S. D. Fidanze, D. Liu, L. A. Hasvold, R. A. Mantei, J. H. Holms,
W. J. McClellan, M. D. Wendt, C. Wada, R. Frey, T. M. Hansen, R. Hubbard, C. H. Park, L. Li, T. J. Magoc, D. H. Albert, X. Lin, S. E. Warder, P. Kovar, X. Huang, D. Wilcox, R. Wang, G. Rajaraman, A. M. Petros, C. W. Hutchins, S. C. Panchal, C. Sun, S. W. Elmore, Y. Shen, W. M. Kati and K. F. McDaniel, J. Med. Chem., 2017, 60, 3828-3850.

60 K. F. McDaniel, L. Wang, T. Soltwedel, S. D. Fidanze, L. A. Hasvold, D. Liu, R. A. Mantei, J. K. Pratt, G. S. Sheppard, M. H. Bui, E. J. Faivre, X. Huang, L. Li, X. Lin, R. Wang, S. E. Warder, D. Wilcox, D. H. Albert, T. J. Magoc, G. Rajaraman, C. H. Park, C. W. Hutchins, J. J. Shen, R. P. Edalji, C. C. Sun, R. Martin, W. Gao, S. Wong, G. Fang, S. W. Elmore, Y. Shen and W. M. Kati, J. Med. Chem., 2017, 60, 8369-8384.

61 E. J. Faivre, D. Wilcox, X. Lin, P. Hessler, M. Torrent, W. He, T. Uziel, D. H. Albert, K. McDaniel, W. Kati and Y. Shen, Mol. Cancer Res., 2017, 15, 35-44.

62 H. Engelhardt, WO2015169962, 2015.

63 H. Engelhardt, L. Martin and C. Smethurst, WO2015022332, 2015.

64 S. Vadivelu, S. Rajagopal, M. Chinnapattu, P. K. Gondrala and D. Sivanandhan, WO2016157221, 2016.

65 D. Liu, J. Pratt, L. Wang, L. A. Hasvold and A. Bogdan, US20140256710, 2014.

66 C. W. Chung, A. W. Dean, J. M. Woolven and P. Bamborough, J. Med. Chem., 2012, 55, 576-586.

67 R. Gosmini, V. L. Nguyen, J. Toum, C. Simon, J. M. Brusq, G. Krysa, O. Mirguet, A. M. Riou-Eymard, E. V. Boursier, L. Trottet, P. Bamborough, H. Clark, C. W. Chung, L. Cutler, E. H. Demont, R. Kaur, A. J. Lewis, M. B. Schilling, P. E. Soden, S. Taylor, A. L. Walker, M. D. Walker, R. K. Prinjha and E. Nicodeme, J. Med. Chem., 2014, 57, 8111-8131.

68 A. Wyce, G. Ganji, K. N. Smitheman, C. W. Chung, S. Korenchuk, Y. Bai, O. Barbash, B. Le, P. D. Craggs, M. T. McCabe, K. M. Kennedy-Wilson, L. V. Sanchez, R. L. Gosmini, N. Parr, C. F. McHugh, D. Dhanak, R. K. Prinjha, K. R. Auger and P. J. Tummino, PLoS One, 2013, 8, e72967.

69 D. Amans, S. J. Atkinson, L. A. Harrison, D. J. Hirst, R. P. Law, M. Lindon, A. Preston, J. T. Seal and C. R. Wellaway, WO2014140076, 2014.

70 K. W. Bair, T. Herbertz, G. S. Kauffman, K. J. KayserBricker, G. P. Luke, M. W. Martin, D. S. Millan, S. R. Schiller and A. C. Talbot, WO2015074064, 2015.

71 N. Schmees, B. Haendler, D. Stöckigt, D. Gallenkamp, R. A. Bissell and R. A. Bouglas, WO2015004075, 2015.

72 P. V. Fish, P. Filippakopoulos, G. Bish, P. E. Brennan, M. E. Bunnage, A. S. Cook, O. Federov, B. S. Gerstenberger, H. Jones, S. Knapp, B. Marsden, K. Nocka, D. R. Owen, M. Philpott, S. Picaud, M. J. Primiano, M. J. Ralph, N. Sciammetta and J. D. Trzupek, J. Med. Chem., 2012, 55, 9831-9837.

73 A. F. Abdel-Magid, ACS Med. Chem. Lett., 2016, 7, 728-729.

74 H. Engelhardt, D. Gianni and C. Smethurst, US20160129001, 2016.

75 J. Blank, V. Bordas, S. Cotesta, V. Guagnano, H. Rueeger and A. Vaupel, US20140349990, 2014. 
76 J. Blank, G. Bold, V. Bordas, S. Cotesta, V. Guagnano, H. Rüeger and A. Vaupel, WO2015075665, 2015.

77 X. Lucas, D. Wohlwend, M. Hugle, K. Schmidtkunz, S. Gerhardt, R. Schule, M. Jung, O. Einsle and S. Gunther, Angew. Chem., Int. Ed., 2013, 52, 14055-14059.

78 M. Hugle, X. Lucas, G. Weitzel, D. Ostrovskyi, B. Breit, S. Gerhardt, O. Einsle, S. Gunther and D. Wohlwend, J. Med. Chem., 2016, 59, 1518-1530.

79 L. A. Hasvold, J. Pratt, K. F. Mcdaniel, G. S. Sheppard, D. Liu, S. W. Elmore and R. D. Hubbard, US20140275079, 2014.

80 L. A. Hasvold, D. Liu, C. H. Park, J. K. Pratt, G. S. Sheppard and L. Wang, WO2013158952, 2013.

81 L. Zhao, D. Cao, T. Chen, Y. Wang, Z. Miao, Y. Xu, W. Chen, X. Wang, Y. Li, Z. Du, B. Xiong, J. Li, C. Xu, N. Zhang, J. He and J. Shen, J. Med. Chem., 2013, 56, 3833-3851.

82 X. Xue, Y. Zhang, Z. Liu, M. Song, Y. Xing, Q. Xiang, Z. Wang, Z. Tu, Y. Zhou, K. Ding and Y. Xu, J. Med. Chem., 2016, 59, 1565-1579.

83 A. M. Ayoub, L. M. L. Hawk, R. J. Herzig, J. Jiang, A. J. Wisniewski, C. T. Gee, P. Zhao, J. Y. Zhu, N. Berndt, N. K. Offei-Addo, T. G. Scott, J. Qi, J. E. Bradner, T. R. Ward, E. Schonbrunn, G. I. Georg and W. C. K. Pomerantz, J. Med. Chem., 2017, 60, 4805-4817.

84 L. Ouyang, L. Zhang, J. Liu, L. Fu, D. Yao, Y. Zhao, S. Zhang, G. Wang, G. He and B. Liu, J. Med. Chem., 2017, 60, 9990-10012.

85 B. Raux, Y. Voitovich, C. Derviaux, A. Lugari, E. Rebuffet, S. Milhas, S. Priet, T. Roux, E. Trinquet, J. C. Guillemot, S. Knapp, J. M. Brunel, A. Y. Fedorov, Y. Collette, P. Roche, S. Betzi, S. Combes and X. Morelli, J. Med. Chem., 2016, 59, 1634-1641.

86 E. von Schaper, Nat. Biotechnol., 2016, 34, 361-362.

87 H. J. Zhong, L. Lu, K. H. Leung, C. C. L. Wong, C. Peng, S. C. Yan, D. L. Ma, Z. Cai, H. M. David Wang and C. H. Leung, Chem. Sci., 2015, 6, 5400-5408.

88 Q. Xiang, Y. Zhang, J. Li, X. Xue, C. Wang, M. Song, C. Zhang, R. Wang, C. Li, C. Wu, Y. Zhou, X. Yang, G. Li, K. Ding and Y. Xu, ACS Med. Chem. Lett., 2018, 9, 262-267.

89 C. Qin, Y. Hu, B. Zhou, E. Fernandez-Salas, C. Y. Yang, L. Liu, D. McEachern, S. Przybranowski, M. Wang, J. Stuckey, J. Meagher, L. C. Bai, Z. Chen, M. Lin, J. L. Yang, D. N. Ziazadeh, F. M. Xu, J. Hu, W. Xiang, L. Y. Huang, S. W. Li, B. Wen, D. X. Sun and S. M. Wang, J. Med. Chem., 2018, 61, 462-481.

90 M. J. Waring, H. Chen, A. A. Rabow, G. Walker, R. Bobby, S. Boiko, R. H. Bradbury, R. Callis, E. Clark, I. Dale, D. L. Daniels, A. Dulak, L. Flavell, G. Holdgate, T. A. Jowitt, A. Kikhney, M. McAlister, J. Mendez, D. Ogg, J. Patel, P. Petteruti, G. R. Robb, M. B. Robers, S. Saif, N. Stratton, D. I. Svergun, W. Wang, D. Whittaker, D. M. Wilson and Y. Yao, Nat. Chem. Biol., 2016, 12, 1097-1104.

91 S. A. Loddick, S. J. Ross, A. G. Thomason, D. M. Robinson, G. E. Walker, T. P. Dunkley, S. R. Brave, N. Broadbent, N. C. Stratton, D. Trueman, E. Mouchet, F. S. Shaheen, V. N.
Jacobs, M. Cumberbatch, J. Wilson, R. D. Jones, R. H. Bradbury, A. Rabow, L. Gaughan, C. Womack, S. T. Barry, C. N. Robson, S. E. Critchlow, S. R. Wedge and A. N. Brooks, Mol. Cancer Ther., 2013, 12, 1715-1727.

92 R. H. Bradbury, D. G. Acton, N. L. Broadbent, A. N. Brooks, G. R. Carr, G. Hatter, B. R. Hayter, K. J. Hill, N. J. Howe, R. D. Jones, D. Jude, S. G. Lamont, S. A. Loddick, H. L. McFarland, Z. Parveen, A. A. Rabow, G. Sharma-Singh, N. C. Stratton, A. G. Thomason, D. Trueman, G. E. Walker, S. L. Wells, J. Wilson and J. M. Wood, Bioorg. Med. Chem. Lett., 2013, 23, 1945-1948.

93 R. H. Bradbury, R. Callis, G. R. Carr, H. Chen, E. Clark, L. Feron, S. Glossop, M. A. Graham, M. Hattersley, C. Jones, S. G. Lamont, G. Ouvry, A. Patel, J. Patel, A. A. Rabow, C. A. Roberts, S. Stokes, N. Stratton, G. E. Walker, L. Ward, D. Whalley, D. Whittaker, G. Wrigley and M. J. Waring, J. Med. Chem., 2016, 59, 7801-7817.

94 G. W. Rhyasen, M. M. Hattersley, Y. Yao, A. Dulak, W. Wang, P. Petteruti, I. L. Dale, S. Boiko, T. Cheung, J. Zhang, S. Wen, L. Castriotta, D. Lawson, M. Collins, L. Bao, M. J. Ahdesmaki, G. Walker, G. O'Connor, T. C. Yeh, A. A. Rabow, J. R. Dry, C. Reimer, P. Lyne, G. B. Mills, S. E. Fawell, M. J. Waring, M. Zinda, E. Clark and H. Chen, Mol. Cancer Ther., 2016, 15, 2563-2574.

95 I. L. AZD5153 in Patients With Relapsed or Refractory Solid Tumors, Clinical-Trials.gov, https:/clinicaltrials.gov/ct2/ show/NCT03205176?term=azd-5153\&rank=1, July 2, 2017.

96 M. Tanaka, J. M. Roberts, H. S. Seo, A. Souza, J. Paulk, T. G. Scott, S. L. DeAngelo, S. Dhe-Paganon and J. E. Bradner, Nat. Chem. Biol., 2016, 12, 1089-1096.

97 J. Lu, Y. Qian, M. Altieri, H. Dong, J. Wang, K. Raina, J. Hines, J. D. Winkler, A. P. Crew, K. Coleman and C. M. Crews, Chem. Biol., 2015, 22, 755-763.

98 T. Shimamura, Z. Chen, M. Soucheray, J. Carretero, E. Kikuchi, J. H. Tchaicha, Y. Gao, K. A. Cheng, T. J. Cohoon, J. Qi, E. Akbay, A. C. Kimmelman, A. L. Kung, J. E. Bradner and K. K. Wong, Clin. Cancer Res., 2013, 19, 6183-6192.

99 C. Y. Fong, O. Gilan, E. Y. Lam, A. F. Rubin, S. Ftouni, D. Tyler, K. Stanley, D. Sinha, P. Yeh, J. Morison, G. Giotopoulos, D. Lugo, P. Jeffrey, S. C. Lee, C. Carpenter, R. Gregory, R. G. Ramsay, S. W. Lane, O. Abdel-Wahab, T. Kouzarides, R. W. Johnstone, S. J. Dawson, B. J. Huntly, R. K. Prinjha, A. T. Papenfuss and M. A. Dawson, Nature, 2015, 525, 538-542.

100 S. Crunkhorn, Nat. Rev. Drug Discovery, 2015, 14, 459.

101 J. A. Doudna and E. Charpentier, Science, 2014, 346, 1258096.

102 I. Churcher, J. Med. Chem., 2018, 61, 444-452.

103 N. Shibata, N. Ohoka, T. Hattori and M. Naito, Curr. Cancer Drug Targets, 2016, 16, 136-146.

104 K. R. Chi, Nat. Rev. Drug Discovery, 2016, 15, 295-297.

105 R. J. Deshaies, Nat. Chem. Biol., 2015, 11, 634-635.

106 K. M. Sakamoto, K. B. Kim, A. Kumagai, F. Mercurio, C. M. Crews and R. J. Deshaies, Proc. Natl. Acad. Sci. U. S. A., 2001, 98, 8554-8559. 
107 M. S. Gadd, A. Testa, X. Lucas, K. H. Chan, W. Chen, D. J. Lamont, M. Zengerle and A. Ciulli, Nat. Chem. Biol., 2017, 13, 514-521.

108 Y. C. Duan, X. Y. Zhai, W. P. Qin and Y. Y. Guan, Acta Pharm. Sin., 2017, 52, 1801-1810.

109 J. S. Lazo and E. R. Sharlow, Annu. Rev. Pharmacol. Toxicol., 2016, 56, 23-40.

110 E. S. Fischer, K. Bohm, J. R. Lydeard, H. Yang, M. B. Stadler, S. Cavadini, J. Nagel, F. Serluca, V. Acker, G. M. Lingaraju, R. B. Tichkule, M. Schebesta, W. C. Forrester, M. Schirle, U. Hassiepen, J. Ottl, M. Hild, R. E. Beckwith, J. W. Harper, J. L. Jenkins and N. H. Thoma, Nature, 2014, 512, 49-53.

111 A. P. Crew, K. Raina, H. Dong, Y. Qian, J. Wang, D. Vigil, Y. V. Serebrenik, B. D. Hamman, A. Morgan, C. Ferraro, K. Siu, T. K. Neklesa, J. D. Winkler, K. G. Coleman and C. M. Crews, J. Med. Chem., 2018, 61, 583-598.

112 Y. H. Jiang, Q. W. Deng, H. Zhao, M. S. Xie, L. J. Chen, F. Yin, X. Qin, W. H. Zheng, Y. J. Zhao and Z. G. Li, ACS Chem. Biol., 2018, 13, 628-635.

113 C. M. Robb, J. I. Contreras, S. Kour, M. A. Taylor, M. Abid, Y. A. Sonawane, M. Zahid, D. J. Murry, A. Natarajan and S. Rana, Chem. Commun., 2017, 53, 7577-7580.

114 A. C. Lai, M. Toure, D. Hellerschmied, J. Salami, S. JaimeFigueroa, E. Ko, J. Hines and C. M. Crews, Angew. Chem., Int. Ed., 2016, 55, 807-810.

115 Y. Demizu, N. Shibata, T. Hattori, N. Ohoka, H. Motoi, T. Misawa, T. Shoda, M. Naito and M. Kurihara, Bioorg. Med. Chem. Lett., 2016, 26, 4865-4869.

116 T. Ito, H. Ando, T. Suzuki, T. Ogura, K. Hotta, Y. Imamura, Y. Yamaguchi and H. Handa, Science, 2010, 327, 1345-1350.

117 D. L. Buckley, I. Van Molle, P. C. Gareiss, H. S. Tae, J. Michel, D. J. Noblin, W. L. Jorgensen, A. Ciulli and C. M. Crews, J. Am. Chem. Soc., 2012, 134, 4465-4468.

118 C. Galdeano, M. S. Gadd, P. Soares, S. Scaffidi, I. Van Molle, I. Birced, S. Hewitt, D. M. Dias and A. Ciulli, J. Med. Chem., 2014, 57, 8657-8663.

119 G. E. Winter, D. L. Buckley, J. Paulk, J. M. Roberts, A. Souza, S. Dhe-Paganon and J. E. Bradner, Science, 2015, 348, 1376-1381.
120 D. P. Bondeson, A. Mares, I. E. Smith, E. Ko, S. Campos, A. H. Miah, K. E. Mulholland, N. Routly, D. L. Buckley, J. L. Gustafson, N. Zinn, P. Grandi, S. Shimamura, G. Bergamini, M. Faelth-Savitski, M. Bantscheff, C. Cox, D. A. Gordon, R. R. Willard, J. J. Flanagan, L. N. Casillas, B. J. Votta, W. den Besten, K. Famm, L. Kruidenier, P. S. Carter, J. D. Harling, I. Churcher and C. M. Crews, Nat. Chem. Biol., 2015, 11, 611-617.

121 D. T. Saenz, W. Fiskus, Y. Qian, T. Manshouri, K. Rajapakshe, K. Raina, K. G. Coleman, A. P. Crew, A. Shen, C. P. Mill, B. Sun, P. Qiu, T. M. Kadia, N. Pemmaraju, C. DiNardo, M. S. Kim, A. J. Nowak, C. Coarfa, C. M. Crews, S. Verstovsek and K. N. Bhalla, Leukemia, 2017, 31, 1951-1961.

122 L. Bai, B. Zhou, C. Y. Yang, J. Ji, D. McEachern, S. Przybranowski, H. Jiang, J. Hu, F. Xu, Y. Zhao, L. Liu, E. Fernandez-Salas, J. Xu, Y. Dou, B. Wen, D. Sun, J. Meagher, J. Stuckey, D. F. Hayes, S. Li, M. J. Ellis and S. Wang, Cancer Res., 2017, 77, 2476-2487.

123 B. Zhou, J. Hu, F. Xu, Z. Chen, L. Bai, E. Fernandez-Salas, M. Lin, L. Liu, C. Y. Yang, Y. Zhao, D. McEachern, S. Przybranowski, B. Wen, D. Sun and S. Wang, J. Med. Chem., 2018, 61, 462-481.

124 K. Raina, J. Lu, Y. M. Qian, M. Altieri, D. Gordon, A. M. K. Rossi, J. Wang, X. Chen, H. Q. Dong, K. Siu, J. D. Winkler, A. P. Crew, C. M. Crews and K. G. Coleman, Proc. Natl. Acad. Sci. U. S. A., 2016, 113, 7124-7129.

125 B. Sun, W. Fiskus, Y. Qian, K. Rajapakshe, K. Raina, K. G. Coleman, A. P. Crew, A. Shen, D. T. Saenz, C. P. Mill, A. J. Nowak, N. Jain, L. Zhang, M. Wang, J. D. Khoury, C. Coarfa, C. M. Crews and K. N. Bhalla, Leukemia, 2018, 32, 343-352.

126 M. Zengerle, K. H. Chan and A. Ciulli, ACS Chem. Biol., 2015, 10, 1770-1777.

127 K. H. Chan, M. Zengerle, A. Testa and A. Ciulli, J. Med. Chem., 2018, 61, 504-513.

128 S. Amorim, A. Stathis, M. Gleeson, S. Iyengar, V. Magarotto, X. Leleu, F. Morschhauser, L. Karlin, F. Broussais, K. Rezai, P. Herait, C. Kahatt, F. Lokiec, G. Salles, T. Facon, A. Palumbo, D. Cunningham, E. Zucca and C. Thieblemont, Lancet Haematol., 2016, 3, e196-e204. 